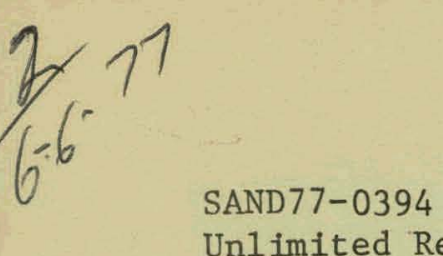

Unlimited Release

UC-2I

OPERATION AND MAINTENANCE MANUAL FOR

DIODE PERFORMANCE ANALYSIS PROGRAM

DIODE $\varnothing$

W. B. Boyer 5242

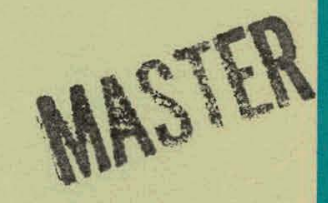

Prepared by Sandia Laboratories, Albuquerque New Mexico 87115

and Livermore, California 94550 for the United States Energy Research

and Development Administration under Contract AT (29.1) 789

Printed March 1977

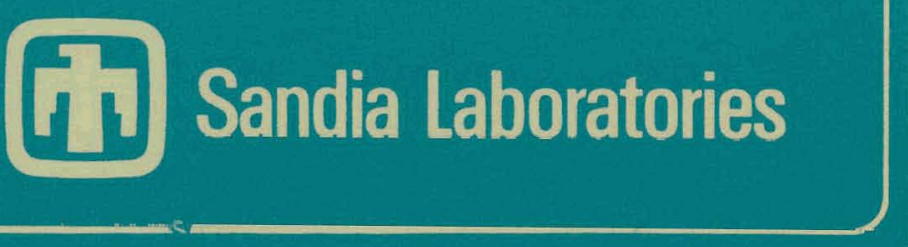

ŞF 2900 Q(7-73) 


\section{DISCLAIMER}

This report was prepared as an account of work sponsored by an agency of the United States Government. Neither the United States Government nor any agency Thereof, nor any of their employees, makes any warranty, express or implied, or assumes any legal liability or responsibility for the accuracy, completeness, or usefulness of any information, apparatus, product, or process disclosed, or represents that its use would not infringe privately owned rights. Reference herein to any specific commercial product, process, or service by trade name, trademark, manufacturer, or otherwise does not necessarily constitute or imply its endorsement, recommendation, or favoring by the United States Government or any agency thereof. The views and opinions of authors expressed herein do not necessarily state or reflect those of the United States Government or any agency thereof. 


\section{DISCLAIMER}

Portions of this document may be illegible in electronic image products. Images are produced from the best available original document. 
Issued by Sandia Laboratories, operated for the United States Energy Research \& Development Administration by Sandia Corporation

\section{NOTICE}

This report was prepared as an account of work sponsored by the United States Government. Neither the United States nor the United States Energy Research \& Development Administration, nor any of their employees, nor any of their contractors, subcontractors, or their employees, makes any warranty, express or implied, or assumes any legal liability or responsibility for the accuracy, completeness or usefulness of any information, apparatus, product or process disclosed, or represents that its use would not infringe privately owned rights. 


\section{PAGES 1 to 2 WERE INTENTIONALLY LEFT BLANK}




\title{
OPERATION AND MAINTENANCE MANUAL FOR \\ DIODE PERFORMANCE ANALYSIS PROGRAM
}

\author{
DIODE $\varnothing^{*}$ \\ by
}

W. B. Boyer

Sandia Laboratories Albuquerque; New Mexico 87115

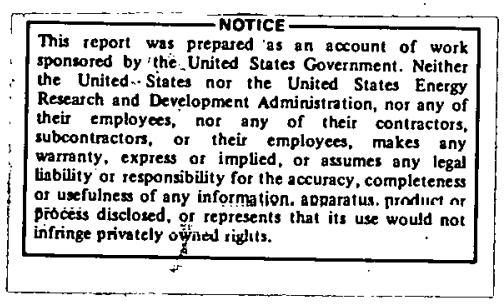

"This work supported by U. S. Fnergy Research and Development Administration under Contract AT(29-1)-789. Printed in the United States of America

Available from

National Technical Information Service

U. S. Dopartment of Commerce

5285 Port Royal Road

Springfield, VA 22161

Price: Printed Copy . ;Microfiche $\$ 3.00$

\author{
Prico: Printed Copy $\cdot$ iMicrofiche $\$ 3.00$
}




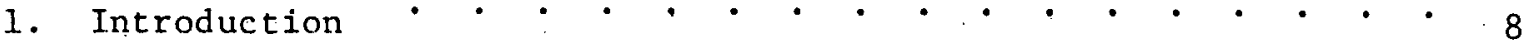

1.1 Program Activation $\cdot \cdot \cdot \cdot \cdot \cdot \cdot \cdot \cdot \cdot \cdot \cdot \cdot \cdot \cdot \cdot$

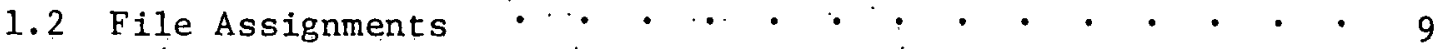

2. General Information $\cdot \cdot \cdot \cdot \cdot \cdot \cdot \cdot \cdot \cdot \cdot \cdot \cdot \cdot \cdot \cdot \cdot 10$

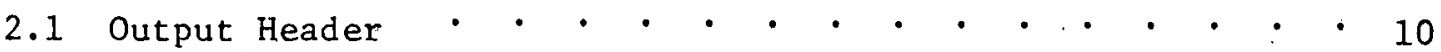

2.1.1 Output Header Format. $\cdot$. $\cdot$. $\cdot$. $\cdot$. $\cdot 10$

2.1 .2 Array Names $\cdot \cdot \cdot \cdot \cdot \cdot \cdot \cdot \cdot \cdot \cdot \cdot \cdot \cdot \cdot 12$

2.1.3 Monitor Entries . . . . • . . . . . . . 12

2.1.3.1 Voltage Monitor $\cdot \cdot \cdot \cdot \cdot \cdot \cdot \cdot \cdot 12$

2.1.3.2 Average Voltage Monitor $\cdot \cdot \cdot \cdot \cdot \cdot \cdot 14$

$2.1 .3 .3 \dot{B}$ Monitor $\cdot \cdot \cdot \cdot \cdot \cdot \cdot \quad \cdot \quad \cdot \quad \cdot 15$

2.1 .3 .4 Average $\dot{B} \cdot \cdot \quad \cdot \quad \cdot \quad \cdot \quad \cdot \quad \cdot \quad \cdot \quad \cdot 16$

2.1.3.5 Corrected Vultage, Inlegrated B,

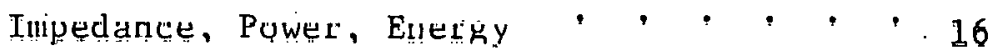

2.1 .3 .6 Current Monitor $\cdot \cdot \cdot \cdot \cdot \cdot \cdot \cdot \cdot \cdot 17$

2.1.3.7 X-Ray Detector Entries : $\cdot \cdot \cdot \cdot \cdot \quad 17$

2.1 .4 Dlode Stațus Entries $\cdot \cdot \cdot \cdot \cdot \cdot \cdot \cdot \cdot \cdot \cdot \cdot 18$

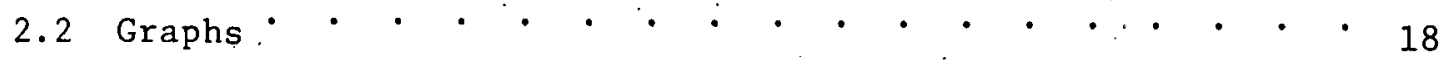

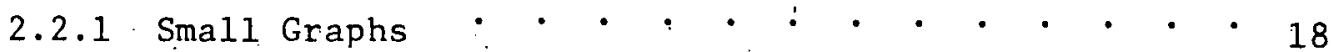

2.2 .2 Large Graphs $\cdot \cdot \cdot \cdot \cdot \cdot \cdot \cdot \cdot \cdot \cdot \cdot \cdot \cdot \cdot \cdot \cdot \quad \cdot 19$

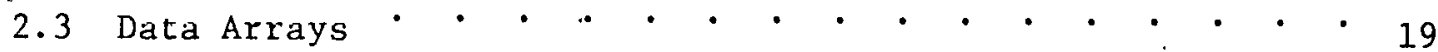

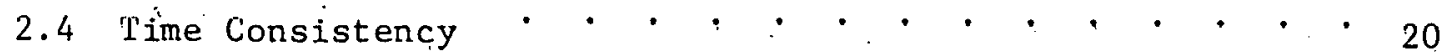

3. Program Operation $\cdot$ • • • • • • • • • • • • •

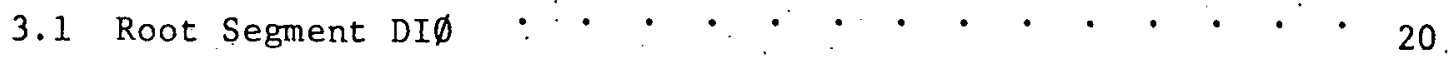

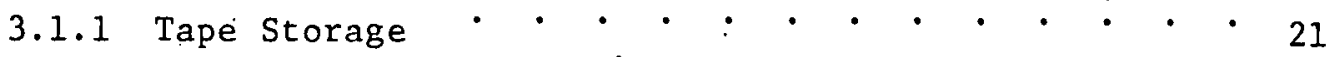


3.1 .2 Exit • • • • • • • • • • • • • 22

3.1.3 Multiple or Differentiating Voltage Monitors • $\quad 22$

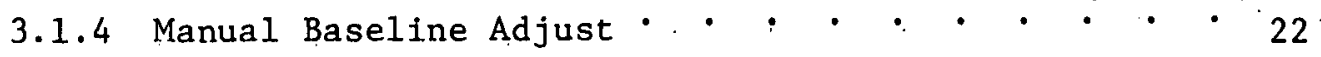

3.1 .5 Signal Averaging • • • • • • • • • • • 23

3.2 Overlay $\operatorname{CDI} \cdot \cdot \cdot \cdot \cdot \cdot \cdot \cdot \cdot \cdot \cdot \cdot \cdot \cdot \cdot \cdot \cdot \cdot \cdot \cdot 23$

3.2 .1 B Baseline Adjust and Integration $\cdot{ }^{\prime} \cdot \cdot \cdot \cdot \cdot 24$

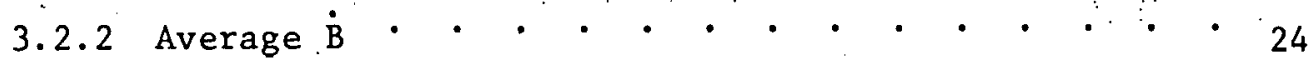

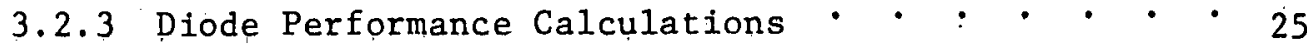

3.2.3.1 Preliminary Steps $\cdot \cdot \cdot \cdot \cdot \cdot \cdot \cdot \quad \cdot 25$

3.2.3.2 Corrected Voltage • • • • • • • • 25

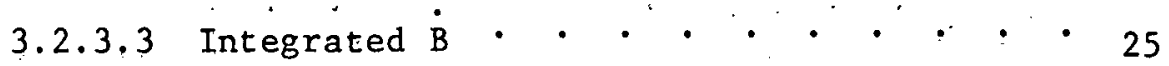

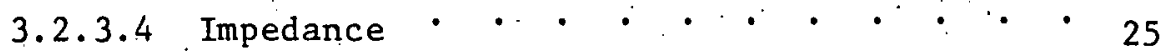

3.2.3.5 Power $\cdot \cdot \cdot \cdot \cdot \cdot \cdot \cdot \cdot \cdot \cdot \cdot \cdot \cdot 26$

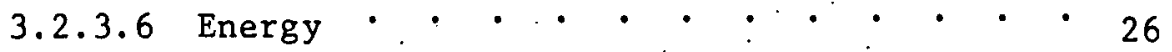

3.2.3.7 Update Disc Locations ' . • . . . 26

3.2 .4 . Current Monitor • : • • • • • • • • • 27

3.2 .5 V Vs I Plot $\cdot \cdot \cdot \cdot \cdot \cdot \cdot \cdot \cdot \cdot \cdot \cdot \cdot \cdot \cdot 27$

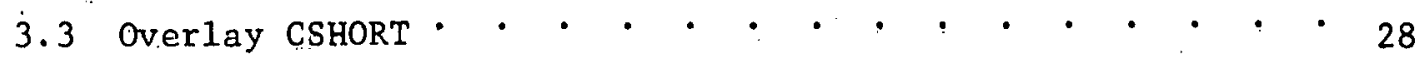

3.3 .1 B Calibration • • • • • • • . • 28

3.3 .2 B-Voltage Comparison • • • • • • • • . 28

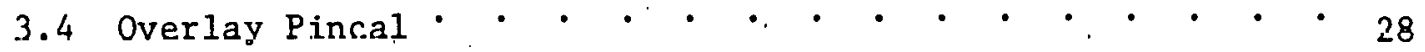

4. Error Messages • • • • • • •

5. Glossary of Variables • • • • • • • • • • • • •

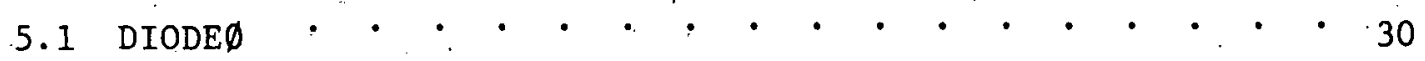

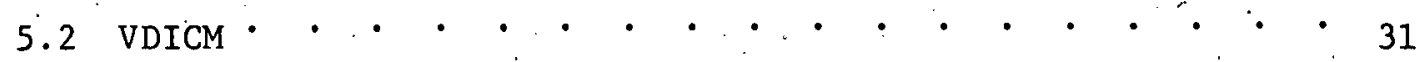

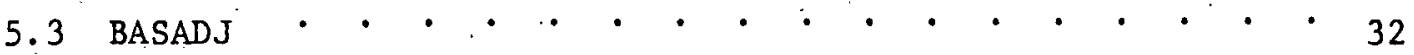


5.4 EBAVER $\cdot \cdot \cdot \cdot \cdot \cdot \cdot \cdot \cdot \cdot \cdot \cdot \cdot \cdot \cdot \cdot \cdot \cdot \cdot \cdot \cdot 33$

$5.5 \mathrm{CDIODE} \cdot \cdot \cdot \cdot \cdot \cdot \cdot \cdot \cdot \cdot \cdot \cdot \cdot \cdot \cdot \cdot \cdot \cdot \cdot \cdot \cdot \cdot \cdot \cdot \cdot 33$

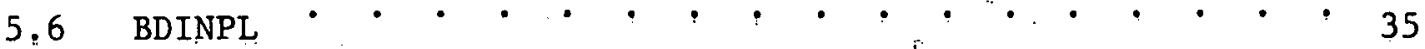

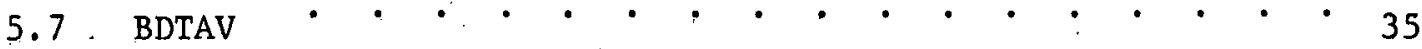

5.8 VIPLOT $\cdot \cdot \cdot \cdot \cdot \cdot \cdot \cdot \cdot \cdot \cdot \cdot \cdot \cdot \cdot \cdot \cdot \cdot \cdot \cdot \cdot 36$

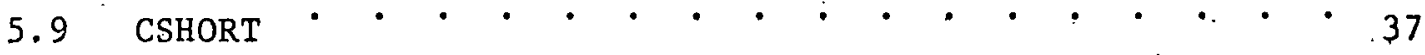

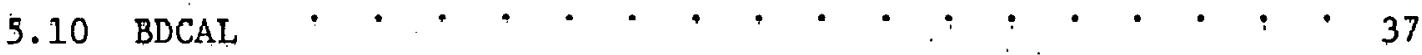

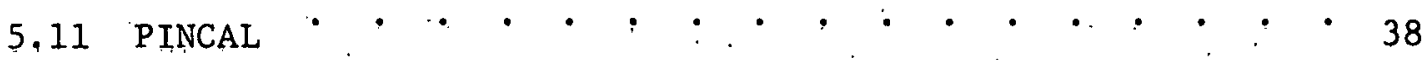

5.12 COMMON AREAS $\cdot \cdot \cdot \cdot \cdot \cdot \cdot \cdot \cdot \cdot \cdot \cdot \cdot \cdot \cdot \cdot \cdot \cdot \cdot \cdot c$

5.12 .1 TAPES $\cdot \cdot \cdot \cdot \cdot \cdot \cdot \cdot \cdot \cdot \cdot \cdot \cdot \cdot \cdot \cdot \cdot \cdot 39$

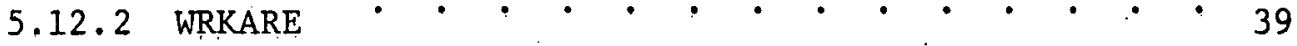

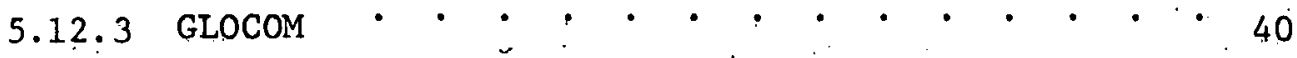

$5.12 .4 \operatorname{MCLCOM} \cdot \cdot \cdot \cdot \cdot \cdot \cdot \cdot \cdot \cdot \cdot \cdot \cdot \cdot \cdot 40$

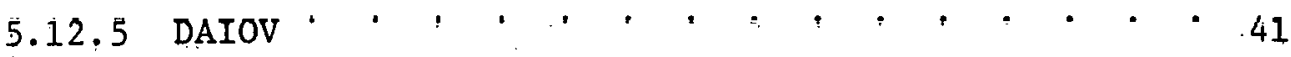

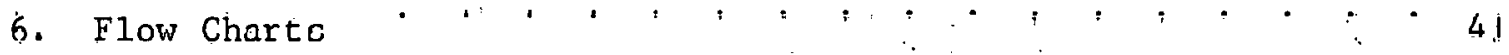

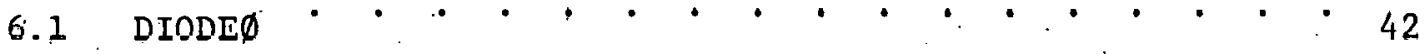

$6.2 \operatorname{VDICM} \cdot \cdot \cdot \cdot \cdot \cdot \cdot \cdot \cdot \cdot \cdot \cdot \cdot \cdot \cdot \cdot \cdot \cdot \cdot \cdot \cdot 45$

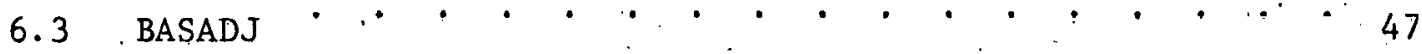

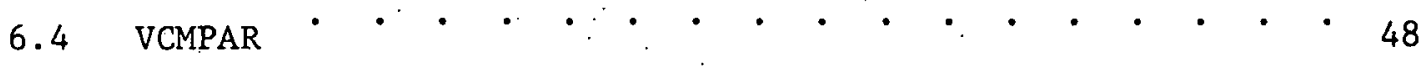

6.5 VMAVER $\cdot \cdot \cdot \cdot \cdot \cdot \cdot \cdot \cdot \cdot \cdot \cdot \cdot \cdot \cdot \cdot \cdot \cdot \cdot 48$

6.6 ERAVER $: \cdot \cdot \cdot \cdot \cdot \cdot \cdot \cdot \cdot \cdot \cdot \cdot \cdot \cdot \cdot \cdot \cdot \cdot \cdot \cdot \cdot 49$

$6.7 \cdot \operatorname{CDIODE} \cdot \cdot \cdot \cdot \cdot \cdot \cdot \cdot \cdot \cdot \cdot \cdot \cdot \cdot \cdot \cdot \cdot \cdot \cdot \cdot \cdot \cdot \cdot \cdot 50$

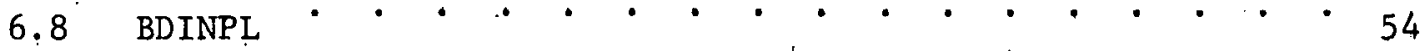

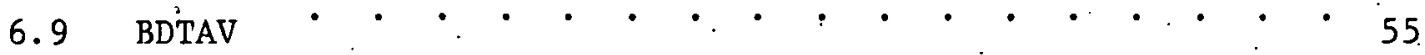

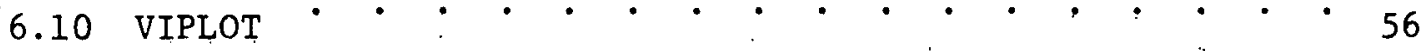

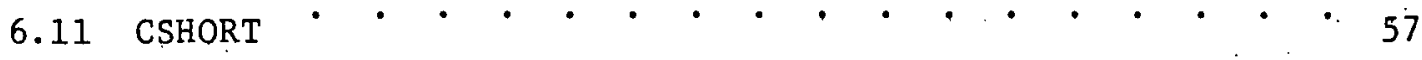




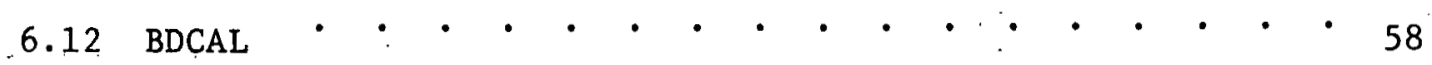

6.13 PINCAL : • • • • • • • • • • • • • • • •

6.14 LOCARA $\cdot \cdot \cdot \cdot \cdot \cdot \cdot \cdot \cdot \cdot \cdot \cdot \cdot \cdot \cdot \cdot \cdot \cdot \cdot 61$

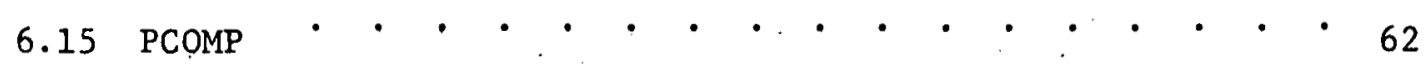

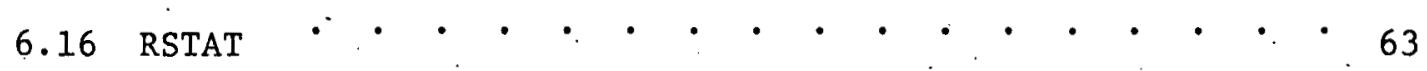

6.17 TSHIFT : • • • • • $\cdot$ • • • • • • • • • •

$6.18 \operatorname{TIMFIX} \cdot \cdot \cdot \cdot \cdot \cdot \cdot \cdot \cdot \cdot \cdot \cdot \cdot \cdot$

$6.19 \operatorname{TCOM} \cdot \cdot \cdot \cdot \cdot \cdot \cdot \cdot \cdot \cdot \cdot \cdot \cdot \cdot \cdot \cdot \cdot \cdot \cdot \cdot \cdot \cdot \cdot 65$

DIODE REFERENCES $\cdot \cdot \cdot \cdot \cdot \cdot \cdot \cdot \cdot \cdot \cdot \cdot \cdot \cdot \cdot \cdot \cdot 66$ 
The purpose of this report is to describe the operation and maintenance of the program DIODE $\varnothing$. This program computes diode performance paraneters for the e beam fusion accelerators HYDRA, PROTO I and PROTO II. The program works in conjunction with other programs in the data acquisition facility library. It reads the input data produced by the Tektronix R7012 Transient Digitizers off the disc. It then computes and plots the diode corrected voltages; impedances, powers, and energies: 


\section{Introduction}

The purpose of this report is to describe the computer program DIODE $\emptyset$. It is written to serve as both an operation and a maintenance manual. The program works in conjunction with other programs in the e-beam data acquisition system library to calculate signals related to machine diode performance. $^{1,2}$ It computes and plots the signal arrays corrected voltage, integrated $\dot{B}$, impedance, power, and energy. It also produces $V-I$ plots with constant impedance and load lines. The program has an overlay segment that will make voltage- $\dot{\mathrm{B}}$ comparisons and current monitor-integrated $\dot{\mathrm{B}}$ comparisons for short circuit shots. Finally the program provides for insertion of other types of data analysis subroutines, e.g., x-ray pin-diode analysis. DIODE $\emptyset$ will hanḍle HYDRA, PROTO $I$ and PROTO II. It will analyze various combinations of used/unused and shorted/unshorted lines for each machine.

\subsection{Activation}

The program DIODE $\emptyset$ is catalogued on disc flle LMT as a foreground task. ${ }^{3}$ It consists of a main or root segment and several overlay segments. The root segment is called DIODE $\emptyset$; it is catalogued under the alias DI $\emptyset$. The.program may be activated from either the console or user 4010 terminal by pressing the appropriate control interrupt. button and typing

$$
\text { GO DIODE (AH). }
$$

This same command can be used to activate the program from FAWTEK or EBD. 1,2 The effect of the optional 'AH' parameter is described in paragraph 2.1.

When the program is activated, it erases the proper terminal screen and types the following messages.

machine, shot number dạte 
When the computer is first turned on, there are no valid machine and shot numbers in core. In this case the first line will be blank. If the machine and shot number are correct, the user should return a ' $Y$ ' to continue the program. If the user wishes to change either entry, he must return an ' $N$ '. The correct machine and shot numbers should be entered in response to the message:

\section{ENTER MACHINE AND SHOT NUMBERS}

The machine entry must be a number. Valid entries are outlined below.

\begin{tabular}{|c|c|}
\hline Entry & Machine \\
\hline 0 & Hydra \\
\hline 1 & Proto $\mathrm{I}$ \\
\hline 2 & Proto II \\
\hline 3 & Special \\
\hline
\end{tabular}

Having the correct machine number is critical since it determines which area of the disc to read and write data arrays. The shot number midy be entered on the same line as the machine number. This entry is optional. If it ie omitted, the last shot number used for the selected machine is read from the disc. This number is then incremented by one to get the shot number for use in the rest of the program. This new shot number is not written back to the disc however. Only the data acquisition program EBD does this. ${ }^{2}$

\subsection{F1la Assigrments}

The task DI is catalogued with the following flle assignments:

1

2

3

10
NO

CR

IP

A01 


$\begin{array}{ll}11 & \text { AI1 } \\ \text { TAP } & \text { MTI } \\ \text { DAT } & \text { ADA }\end{array}$

\begin{abstract}
ADA:
In addition there are four vacant file assignment positions. File assignments may be tested or altered by the Operatior Communications TASSIGN or ASSIGN directives respectively. All data arrays are read from or written to disc direct access filè 23 .
\end{abstract}

2. General Information

This section covers topics which apply to all segments of DIØ. It describes output header entry requirements, plots, and data arrays.

\title{
. 2.1 Output Header
}

The entries in the output header determine which overlays will be run on a shot. ${ }^{2}$ They also serve as pointers to the location on disc of various input and output arrays. A different output header is stored on disc for. each machine. The first thing DI $\emptyset$ does after machine and shot number selection is to read into core the appropriate output header. Normally this is the output header corresponding to the machine selected. However if the program is activated with the 'AH' option, the output header for the 'Special'. machine is read into core instead. This alternate header is normally placed on disc by a FAWTEK shot tape read operation. The 'AH' option characters are stored in the fifth word of GLOCOM (5.11.3).

\subsubsection{Output Header Format}

The output header is a variable length two dimensional array consisting of up to 80 rows of four words each. A diagram showing the significance of each word is given in Table 1. All entries except POWER and ENERGY are placed in the table by EBD. 2 
Table I Dutput Header

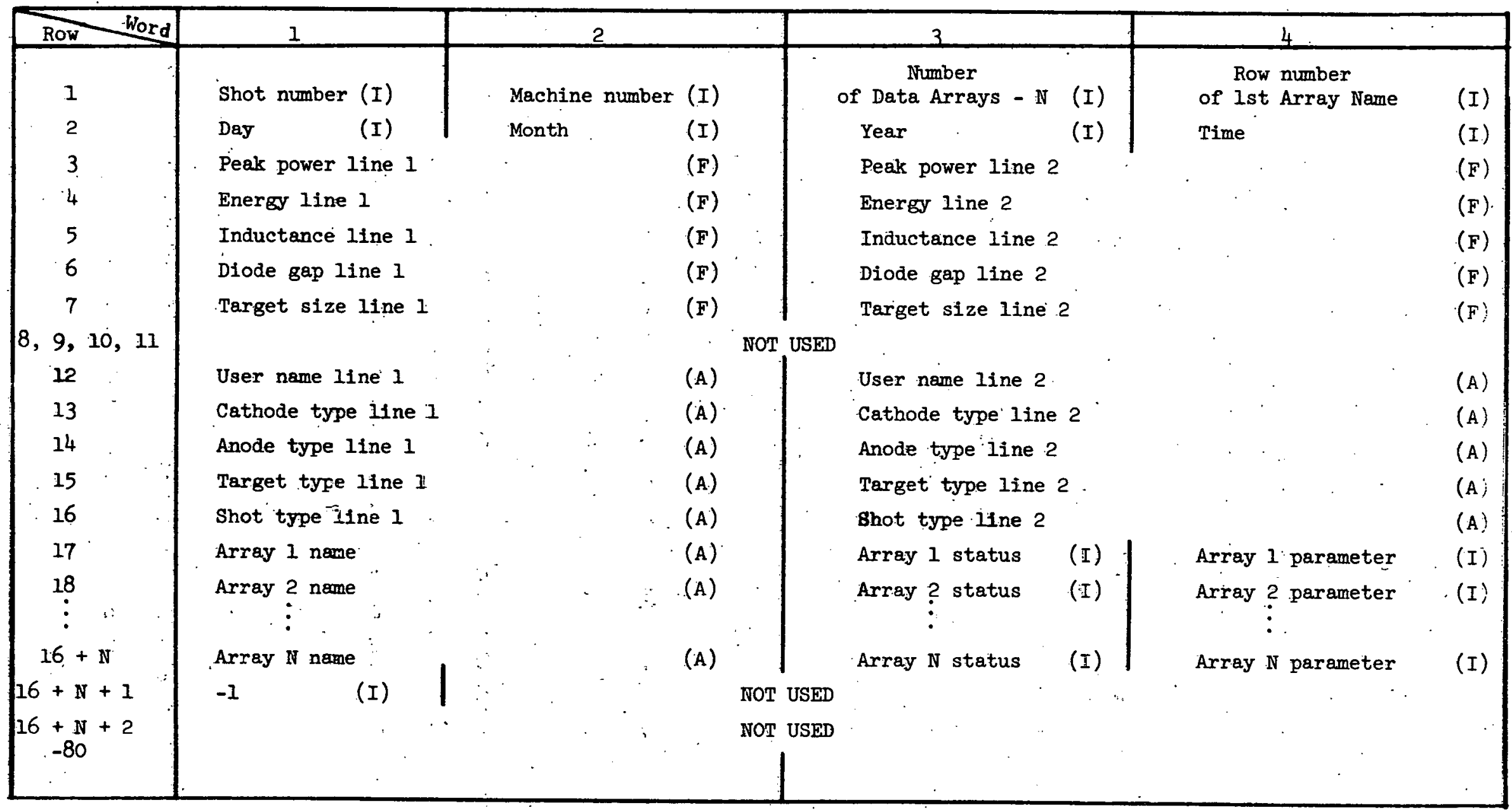




\subsubsection{Array Names}

The program DI needs to know where several key arrays are located on disc file 23. It finds them by searching for arrays with specific names in the output header array name list. The position of the array name in the list corresponds to the array record position on file 23 . A name search function is used to find the position in the list of array names. The function first looks for an array name that matches all four characters in the requested name. If it can't find one, it looks for an array name that matches the first two characters in the requested name. If there is more than one array name whose first two characters match the call name, the location of the first such array is returned. If no array name in the output header matches at least the first two characters in the requested name, a value of -1 is returned to indicate the error condition.

\subsubsection{Monitor Entries}

The program DI $\emptyset$ must have entries for at least one voltage monitor and at least one $\dot{B}$ for each machine line in use. If a line is not shorted, it must also have a corrected voltage entry followed by integrated $\dot{B}$, impedance, power, and energy entries. Current monitor and $x$-ray pin diode entries are optional. A description is given for each monitor entry including requirements for ID, STATUS, and PARI columns:

\subsubsection{Voltage Monitor}

There must be at least one voltage monitor for each line in use. The first two characters in the names of the monitors used must be 'VM'. If both machine lines are used, the voltage monitor entries for the second line must immediately follow those for the first line. If a machine line has only one monitor and it is a direct, i.e. not differentiating, monitor, PARl must be zero. In this case the STATUS column is not examined: 
If there is more than one monitor or the monitor differentiates the signal, the number of monitors for the line must be placed in the PARl column for the first machine line entry.. If the operator wishes to average some or all of the voltage monftors, he must enter the negative of the number of monitors. The bits in the STATUS entry then have the following oignificance for each monitor on the line,

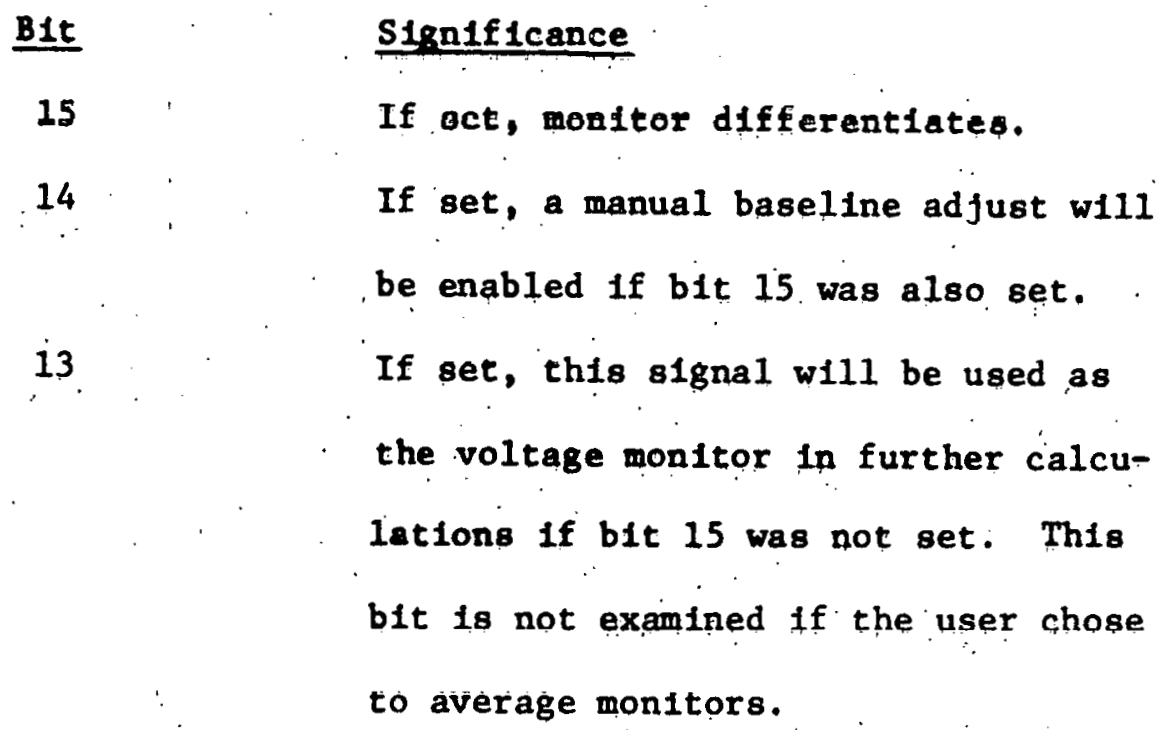

Bit 15 is the least significant bit in the 16 bit binary integer word. Thus bits being set correspond to different integers from 0 - 7. The formula for computing a number corresponding to bits being set is

$$
\begin{aligned}
N & =\Sigma s_{15-12^{(15-1)}} \\
1 & =0 \\
s_{j} & =1 \quad \text { if tit } j \text { ts set, } \\
& =0 \quad \text { if bit } j, 1 \mathrm{~s} \text { not set. }
\end{aligned}
$$

Example: bits 15, 13, 12 set

$$
\begin{aligned}
& \text { (12) (13) } \\
& \mathrm{N}=1 \cdot 2^{3}+1 \cdot 2^{2}+1 \cdot 2^{0} \\
& =13
\end{aligned}
$$


If differentiating voltage monttors are used; there must be an entry in the output header to contain the integrated array for each input. Since these entries correspond to computed rather than measured arrays, the entrles must follow all input array entrles. The first such entry must be name 'VMDI'. Succeeding entry names must start with 'VM'. If bit 13 is set in the STATUS word for one of these entries, that signal will be used as the voltage monitor in the rest of program: Only one array may be so designated. If more than one entry has STATUS b1t $13 \mathrm{set}$, only the signal corresponding to the first entry w1ll be used.

If more than one voltage monitor is present, a comparison can be made of each voltage signal to the first voltage signal. In the case of differentiating monitors, the integrated version of the signal is used. The PARI column for the appropriate entry gives the mode of comparison.

$\underline{\text { PARl }}$

$-1$

0

1

2

\section{Meaning}

no comparison will be made. comparison with no baseline shift. comparison with constant baseline shift." couparison with constant and sloping beseline shift.

\subsubsection{Average matioge monttor}

If the operator has elected to average the voltage monitors, there must be an entry in the output header with the name 'VTAV'. This entry should follow all input array entries. If the monttors on both machine Iines are to be averaged, the average entry for the second. Ine must immediately follow the 'VTAV' entry. The STATUS and PARI columns are not examined for elther entry. 


\section{$2.1,3.3$ B Monitor}

There must be at least one $\dot{B}$ monitor for each machine line In use. The first two characters In the names of the monitors must be 'BD'. Any additional $\dot{B}$ monitors for the first machine line must immediately follow the first entry: $\dot{B}$ entries for the second diode must follow those for the first. The effect of various bits being set in the STATUS entry are described below.

STATUS Bit

14

13

12

\section{Effect if Bit Set}

$\dot{B}$ is uncalibrated. No computations of corrected voltage, impedance, power and energy will be made. $\dot{B}$ will be integrated and compared to current monitor on short circuit shots. Baseline adjust option is selected in $\dot{B}$ integrate subroutine. Thio causes the corrected voltage to be computed by sibtracting $L^{*} \dot{B}$ from the previous corrected voltage instead of the voltage monitor. The inductance used is taken from the entry PARI parameter. The Inductance entry is in nanohenrys. This option is only valld when there is at least one previous $\mathrm{B}$ for the same line. Thls bit set causes this $\dot{B}$ algnal to be subtracted from the previous one, and the result will be integrated. All such currents will be plotted on a large grid. 
The PARI column for the firat $B$ for each machine ilne must contain the number of $\dot{B}$ monitors used for the 11ne. If PARl to negative, the user will be given the option of averaging any or all of the $\dot{B}$ signals for use in computing corrected diode voltage, impedance, powen, and energy. If PARl is positive, a separate calculation of corrected voltage, impedance, power and energy will be made for each $\dot{B}$.

\subsubsection{Average : $\dot{B}$}

If the $\dot{B}$ signals for a given line are to be averaged; $1 . e$. PARl less than zero for the first $\dot{B}$; the entry immediately preceeding the corrected voltage entry must start with the letters 'BA'. The averaged $\dot{B}$ signal will be written to the corresponding position on disc file 23. The columns STATUS and PARl are not used.

2.1.3.5 Corrected Voltage, Integrated $\dot{\mathrm{B}}$, Impedance, Power, Energy

If the CDIODE loverlay is to be used and the $\dot{B}$ signals are calibrated for a given line, at least one corrected voltage entry is required. The first two letters of corrected voltage entries must be 'VC'. Each corrected voltage entry must be immediately followed by integrated $\dot{B}$, impedance, power, and energy entries in that order. The names of these entries are not examined. If there is to be more than one group of machine parameter calculations for a given line, 1.e. the first $\dot{B}$ PARl entry greater than 1 , these group entries must follow the first one. And the within group entry order must be the same as for the first group. Groups of machine parameter signals for the second line (1f used) must immediately follow those for the P1rst. The STATUS and PARI colunns are not used. 


\subsubsection{Current Monitor}

The current monitor entry is optional except in the case of uncalibrated $\dot{B}$ signals on short circuit shots. The names of current monitors entries must start with the two letters 'CM'. If there is also a current monitor for the second machine line, it must immediately follow the first. If there are two current monitors, PARI must be a 1 for the first one. If there is only one and it monitors the first machine line; PARl must be zero. If it monitors the second line, PARI must be a 2 .

\subsubsection{X-Ray Detector Entries}

The following paragraphs describe the output header entry requirements for the $\mathrm{x}$-ray signal analysis overlay PINCAL.

All input array names must start with the two characters 'XR'. All input entries must be in an uninterrupted group. The PARl column for the first input entry must contain the total number of pin diodes in the shot. The STATUS entry for the first pin diode entry has the following effects if there is more thain one entry.

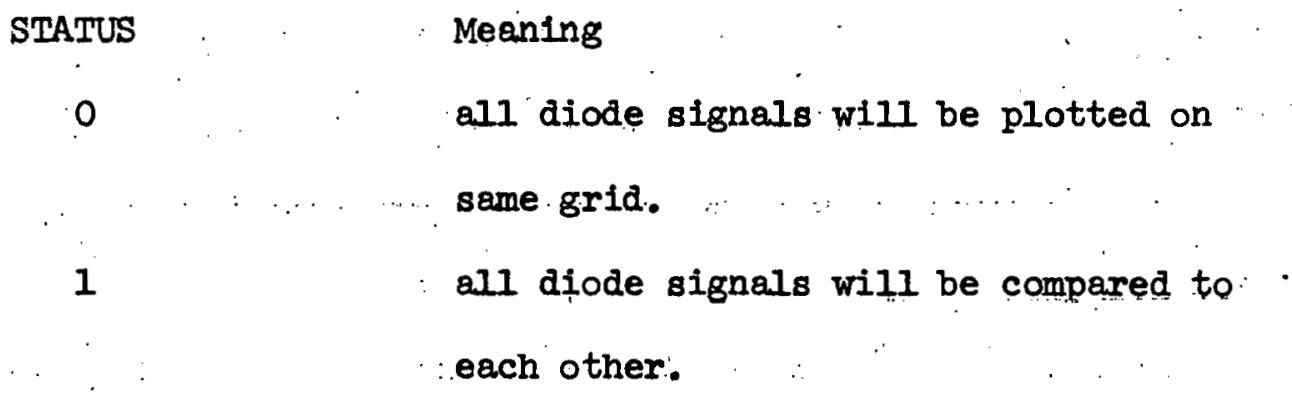

This STATUS and PARI columns for entries after the first are rot used. The entry: name for the first integrated pin diode signal must be 'XRII'. Entries for integrated signals for the other pin diode signals must immediately follow the f1rst. These entries are optional. If they are not present, the integrated aignal will not be stored on disc. And the graph titlle for the integrated signal w11 be the same as that for the non-integrated graph. 
Either all the integrated signal entries should be present; or none should be present. The STATUS and PARI entries are not used. If the output header 'contains an entry name starting with ' $P \mathrm{O}^{\prime}$ ', the first input pin diode signal' will be compared to this array. If there is more than one entry name starting with 'PO', the first such entry will be used.

\subsubsection{Diode Status Entries}

The first section of the output header as printed out in EBD contains two rows of diode status information. The first row refers to the north machine Iine on HYDRA and the top machine line on PROTO I and PROTO II. The second row refers to the south or bottom machine lines respectively. The only entries used by program DI $\varnothing$ are GAP, INDUCT, SHOT and USER. If the GAP entry is greater than zero, the overlay CDI will be run. If the first two letters of the SHOT entry are ' $\mathrm{SH}$ ', the CSH overlay will be run. The value entered for INDUCT will be used as the line inductance for computing corrected voltage. 'If the USER entry for the first line is 'SKIP', no calculations will be made for this line regardless of what any other header entries are. This option should only be used on the first line when the output header contains entries that pertain to that line.

\subsection{Graphs}

The subroutines in DI $\varnothing$ draw plots of measured and calculated data arrays on the 4010 screen. Generally the signal name in the output header will be used as the graph label. There are two different types of plots used: Each type is discussed below.

\subsubsection{Small Graphs}

Most single array plots are drawn on a $2^{\prime \prime} \times 2^{\prime \prime}$ grid. There will be a maximum of four such plots per page. The computer draws all the graphs for a page and then waits for the operator to return a status parameter. 
The computer may stop with fewer than four plots on the page. The program prints out the current machine and shot numbers when it finishes a page. This is the signal to the operator that there will be no more plots on the page. The operator must then return a status parameter to the program: Status is returned by typing a one digit number between 0 - 9 followed by RETURN. Simply striking the RETURN key or any alphabetic character followed by RETURN causes a status $=0$ to be returned. The effect of the status parameter is as follows.

$\begin{array}{cl}\text { Status } & \\ 0 & \text { generates a hard copy and allows } \\ & \text { program to continue. } \\ & \text { causes program to immediately exit } \\ & \text { with no further operation. } \\ 1-4,6-9 & \text { allows program to continue without } \\ & \text { generating a hard copy. }\end{array}$

\subsubsection{Large Graphs}

All multiple plots are arawn on a $4.5^{\prime \prime} \times 4.5^{\prime \prime}$ square gria. This is the largest square grid that will fit on the screen and still leave room for axis labels. The first plot will be draw with a solid line. Subsequent plots will be drawn with dotted lines. Each, curve will be labeled with a single letter or number. After the last plot is drawn, machine and shot numbers are printed out. This is followed by an ordered listing of the names of each signal plotted. The operator must then return a status parameter as described above.

\subsection{Data Arrays}

All data arrays processed by the task DI $\varnothing$ are assumed to be in the standard system format. 3 


\subsection{Time "Consistency}

Many diode pärameter calculations involve mathematical operations on two arrays. The elements of one array may be added to, subtracted from, multiplied by; or divided by the elements of a second array. However the two arrays may not be time consistent as produced by the data acquisition program EBD. They may start at different times (array elements 515 are not equal). And they may have different sampling intervals (array elements 2 are not equal). The subroutine TIMFIX is used to make two arrays time consistent. It first modifies each array so that the first data point corres-

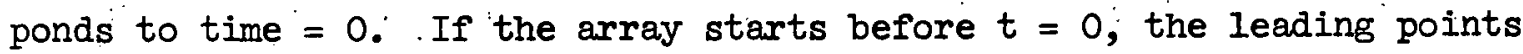
before $t=0$ are "aropped. If the array startes after $t=0$, data values of zero are inserted in the array between $t=0$ and the time at which the first point originally occurred. In both cases array element 515 is set to zero, and the new number of points is placed in element 1 .

If the two arrays have different sampling intervals, the array with the longer interval is transformed so that it also has the shorter interval. The method used is linear interpolation. The subroutine TCOM performs the transformation. Finally the number of points in the two arrays are set equal. The value used is the smaller of the two original ones.

\section{Program Operation}

\subsection{Root segment DI $\varnothing$}

The root segment DI $\varnothing$ is always in core when the task is active. After the proper machine and shot number have been selected, it first reads into core the appropriate output header. It then searches the array name list for the first voltage monitor, $\dot{B}$ monitor, current monitor, and corrected voltage entries. If the voltage monitor PARI entry is greater than zero, 
the progrem calls the overlay VDICM to hande multiple or differentiating voltage monitors. It then examines the USER entry to see if the machine Iine calculations should be skipped. If the skip option is not selected, the program examines the GAP and SHOT entries to determine whether to run the overlays CDI and CSH. Before elther overlay is actually loaded, the program checks to make sure that both a voltage and a $\dot{B}$ monitor are present. If either is missing, an error message is printed out; and the program exits.

After the segment DI finishes with the Plist machine Ine, it updutus the pointers to various arrays and repeats the process described above for the second line. After it has finished with the machine diode performance calculations, it may call other special purpose overlays or subroutines. These will depend on what experiments are going on. To include a spectal subroutine, it, must first be compiled and stored on the User Iibrary. ${ }^{3}$ The root program DIODE $\varnothing$ must then. be re-edited and recatalogued onto file IMT. If both machine diodes were used on the shot, the program calis the overlay TPBTVI. This program plots the machine voltage and current for both lines on omall gride.

\subsubsection{Tape Storage.}

When all calculations have been completed, the program types the message:

ENTER 1 TO PUT DATA ON TAPE. ANYTHING ELSE STOPS PROGRAM. If the user wishes to store the data on tape, ho shulla enter a 1 followed by RETURN. Any other entry will skip the taping process. If taping is . selected, the data.will be transferred from disc to tape in the manner described in reference 3. 


\section{1 .2 Brest}

When the program DIODE $\phi$ exits, it always activates the manual control task. "Th1s prosram w1ll signify 1 ts presence by typing:

READY

The operator then has 8 seconds to type in which program he wants next if any:

\subsubsection{Multiple or Differentiating Voltage Monitors}

The overlay VICM handles multiple and/or differentiating voltage monitors. It first gets the number of monitors from the PARI entry for the first monitor. If STATUS bit 14 is set for any differentiating monitors, the subroutine calls the baseline adjust program BASADJ for that signal. This program is described in 3.1.4. The program VDICM then reads in and plots each input signal. If the monitor is the differentiating type, the signal is then integrated and plotted. The integrated signal is copied to disc in the record position given by the corresponding output header entry. If there is more than one voltage monitor, all voltage signals may then be sequentialiy compared to the first one. The integrated versions are used In the case of differentiating montors. If voltage monttor averaging was selected the program searches the output header for the 'VTAV' entry. If none is found, an error message is printed; and the program exits. If 'VTAV' is present, the subroutine EBAVER is called to perform the selection and averaging process. This program is described in 3.1.5. If averaging" was not selected, VDICM searches all voltage signals to determine which one is to be used in further calculations. If no voltage signal has bit 13 set, an error message 1s printed; and the program exits.

\subsubsection{Manual Baseline Adjust}

The subroutine BASADJ gives the operator the ability to manually adjust the baseline of input signal arrays which must be integrated. This 
process is sometimes necessary since mall baseline shifts in a signal result in an unacceptable ramp when the signal is integrated. The program reads the array from the disc and plots. It on a large grid. It then activates the terminal crosshair cursors. The operator then adjust the horizontal cursor to where he wants the baseline to be. This location is returned to the computer by striking any alphanumeric key followed by . RETURN. The value associated with the crosshatr position is subtracted from the signal. The new gignel and Its integral are then plotted on small. Brids. This followed by the messege:

$$
\begin{aligned}
& \text { VALUE SUBTRACTHD = } \\
& \text { ENITER I TO RETRY }
\end{aligned}
$$

By returning a status of 1 the baseline adjust process will be repeated. Other status entries are treated is described in 2.2.1. When the operator. is satisfled, the new signal is written onto the disc in place of the old one. Ail values subtracted are accumulated and stored in array element 514.

\subsubsection{S1gnal Ayeraging (ERAVER)}

The subroutine EBAVER is used to allow the operator to select and average either voltage monitor or $\dot{B}$ signals. The program starts by erasing the screen and typing

ENTER SIGNAL NUMBERS TO BE AVERAGED 1-n.

The number ' $n$ ' will be the absolute value of the approprlate PAR! entry. The operator must then enter the number(s) of the signal(s) he wishes to average. For example if he wishes to average the first; second, and third signals, he should enter:

$$
1,2,3 .
$$

The program then reads in the selected signals from the disc and averages them. The averaged signal is left in WRKARE array A (5.11.2) for the calling program to store on disc. 


\section{2 overlay CDI}

The CDI overlay computes varlouis diode parameters. It plots all computed curves on the 4010 screen. The program also plots the current monitor (if any) and a V Vs. I plot with constant impedance lines and load lines. The actual computations made are described in the following sections.

\subsection{1 $\dot{B}$ Baseline Adjust and Integration}

If there is more than one B signal or if the baseline adjust option is selected $(2.1 .3 .3)$, the overlay will call the subroutine BDINPL. If the baseline adjust option is selected, the subroutine BASADJ will be called to accomplish the shift. This subroutine is described in 3.1.4. After all the selected $\dot{B}$ signals have been baseline adjusted, the subroutine plots them all together on a large grid.

If any $\dot{B}$ after the first has output header STATUS bit 12 set, it will be subtracted from the previous signal; and the result will be inte-: grated. All such difference currents will be plotted together on a large ǵrid and appropriately labeled.

\subsubsection{Average B}

If there is more than one $\dot{B}$ for a given Iine and the user has elected to average them, the overlay will call the subroutine BDTAV. This subroutine reads and plots each $B$ on 1ts own small grid.; If the entry name Immediately preceeding corrected voltage does not start with 'BA', and error message is printed; and the program exits. 'Otherwise the averaged signal will be written to the corresponding record on disc file 23. The location of the $\dot{B}$ signal for the rest of the calculations on this line is set equal to this record number. The number of $\dot{B}$ signals is set to 1 . The subroutine EBAVER (3.1.5) actually performs the averaging process. 


\subsubsection{Diode Parameter Calculations}

\subsubsection{Preliminary Steps}

The overlay CDIODE next reads the proper measured.line voltage array off the disc: and plots. It on a small grid. It then reads and plots the first $\dot{B}$ array from disc. If the $\dot{B}$ is uncalibrated, 1.e. STATUS bitt 15 set, no further processing 1s.done using this signal. If the $\dot{B}$ is calibrated, it is made time consiotent with the measured voltage array as described in 2.3 .6 .

\subsubsection{Corrected Voltage}

The program makes sure there is a valid entry in the output header for the corrected voltage array. If there is none, an error message is printed out; and the program exits. The corrected voltage signal is computed by a point-by point subtraction of the $\mathrm{L}$ di/dt term from either the measured voltage or a previous corrected voltage.

$$
V(I)=\dot{V}(I)-L * \dot{B}(I) \text {. }
$$

The inductance $L$ is either the line INDUCT entry or PARI * $10^{-9}$. for a $B$ with STATUS bit 13 set. The corrected voltage is plotted on a small graph and written to disc.

\subsubsection{Integrated $\dot{\mathrm{B}}$}

The $\dot{B}$ array io transferred to a diode current array. The array is then integrated to get the diode current. The integrated $\dot{B}$ or current array is plotted on a small grid and written to the disc record immediately following the corrected voltage.

\subsubsection{Impedance}

The diode impedance is computed by a point by point division of the corrected voltage array by the current array. If the resulting value is greater than the machine maximum ZMAX, or less than zero in 
the first $90 \%$ of the array, the Impedance is set equal to ZMAX. This is done to insure proper scaling when plotting. If the signal is outside the 0-ZMAX limits in the last $10 \%$ of the array, it is set to zero. The values of ZMAX used for the specific machines are:

$\begin{array}{lc}\text { HYDRA } & 10.0 \text { ohms } \\ \text { PROTO 1 } & 20.0 \text { ohms } \\ \text { PROTO 2 } & 5.0 \text { ohms }\end{array}$

The impedance array is then plotted on a small grid and written to the disc record following the current.

\subsubsection{Power}

The diode power is computed by doing a point by point multiplication of the corrected voltage and current arrays. The power data wipes out the impedance array. After the entire power array has been computed, the peak power is found and stored in the output header in the POWER location for the appropriate machine line. The power array is then plotted on a smail grid and written to disc record following impedance.

\subsubsection{Energy}

The diode energy is computed by integrating the power array. The integration is done in place and thus destroys the power data. The maximum value of the energy array is found and stored in the output header in the ENERGY location for the appropriate machine line. The peak power and energy values are written in the lower center portion of the present 4010 page. The energy array is then plotted on a small grid and written to the disc record following power.

\subsubsection{Update Disc Locations}

After the overlay CDIODE has completed the operations described above for one $\dot{B}$, It increments the corrected voltage pointer by 5 and the $\dot{B}$ pointer by 1 . If there is anothw $\dot{B}$ to be processed, the 
program redoes the operations described above. However if the B STATUS bit 13 is set, the corrected voltage just computed is used instead of the voltage monitor; a new inductance is taken from the $\dot{B}$ PARl entry; and ZMAX is set to 50 ohms.

\subsubsection{Current Monitor}

If there is a current monitor on the machine line, it is plotted on a small grid after the last energy plot.

\section{$3.2 .5 \mathrm{~V}$ ve I plot}

The overlay CDIODE next calls the subroutine VIPLOT. Th1s subroutine reads in from the disc the flrst corrected voltage and integrated $B$ arrays. It plots them on a large grid with voltage on the vertical axis and current on the horizontal axis. It then plots three constant impedance Iines corresponding to three different imedances. It also plots four load lines corresponding to different Marx voltages on the same grid. Constant impedance and load lines are plotted with dotted lines. Only the portion of these lines that lie within. the grid will be plotted. Finally the subroutine prints out the impedance and Marx voltage values used in making the auxiliary plots. The impedance values used are:

HYDRA $\quad 1.0,2.0,4.0$ ohms ,
PROTO I $\quad 3.5,7.0,14.0$ ohms ,
PROTO II $.25, .50,1.0$ ohms :

The Marx voltage and impedance values used for the load lines are:

HYDRA

$2.0,3.0 \mathrm{MV}, 2$ ohms,

PROTO I

$1.5,2.0,2.5,3.0 \mathrm{MV}, 7.2$ ohms

PROTO II

$1.5,2.0 ; 2.4,3.0 \mathrm{MV}, .5 \mathrm{ohm}$. 


\section{3 overiay CSHORT}

This overley is used to calibrate $\dot{B}$ signals and to coupute ine inductances and signal time delays for short clrculted diode shots.

\subsubsection{B Calibration}

The program first examines the STATUS parameter for each B array. If the signal is uncalibrated, the subroutine BDCAL is called. However if the current monitor signal is missing, an error message is printed; and the program exits. If the baseline adjust option for the $\dot{B}$ is selected, the subroutine BASADJ will be called. This progrem is described in 3.1 .4 . The BDCAL program reads in the $\ddot{B}$ and current monitor arrays from the disc. It integrates the $\dot{B}$ signal and plots all three signals on small grids. The program then compares the integrated $\dot{B}$ to the current monitor us ing the current monitor as the known signal. The two arrays will be plotted superimposed on a large grid, and the $\dot{B}$ scale factor and time shift will be printed out.

\section{$3.3 .2 \dot{B}$ - Voltage Comparison}

After the overlay CSHORT: examines each $\dot{B}$ for calibration, it reads in and plots the line voltage monitor signal on a large grid. Next it reads and plots the first $\dot{B}$ signal also on a large grid. The program then compares the voltage and $\dot{B}$ and plots them supertrposed on a large grid. The scale factor printed out will be the line inductence if both the olgnals are callbrated. The $B$ read, plot, and comparison is done for each $\dot{B}$ on the 1 ine.

\subsection{Overlay PINCACI}

This program processes $x$-ray pin diode signals. It is called by DI $\varnothing$ after the diode parameters for both lines have been computed. The program

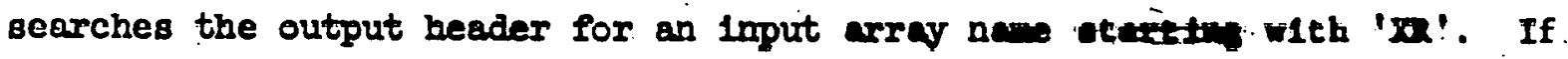
none is found, the subroutine returns wtbout worther celculations. 
Otherwise it searches for the flrst outgut array entry. It then reads in an input array tram disc and plots it on a mall grid. It integrates the signal and plots the integral on a amall grid. If there is a place for the integrai in the output header, the integral is copied to disc. This is done for each input pin signal. After all pin signels have been integrated and plotted, the program decides whether any comparlsons ar overlay plots were requested.

If there is more than one input and comparisons were requested, all Input signals are compared to each other. Otherwise if there is more than. one input; all. the pin signals w1ll be plotted overlayed on a large grid. Finally the program searches the output header for a power array. If one is located, a comparison is made of the power signal to the first input pin diode signal. The power signal is treated as the known array. 4. Error Messages

Error messages are printed out on the 4010 screen in the following format:

$$
\text { FRROR * name, CLUE = NF, UNIT = I1ne }
$$

Errors are produced when the program cannot find certain array names in the 'output header ('NF' means 'not found'). The 'line' parameter is the line number for which the error was detected. The specific errors are described below.

$\begin{array}{ll}\text { 'Name' } & \text { Meaning } \\ \text { VMBD } & \begin{array}{l}\text { Voltage monitor or } \dot{B} \text { entry is missing. } \\ \text { VMDT }\end{array} \\ \text { CORV } & \text { Voltage monitor error in VDICM. } \\ \text { BDAV } & \text { Corrected voltage entry is missing. } \\ \text { CMON } & \text { Average } \dot{B} \text { entry is missing }\end{array}$




\section{Gloseary of Variable}

The following lists are glossarles of varlables used in the major subroutines in the DIODED-task.

\subsection{DIODED}

$\operatorname{GAP}(2)$

- cathode-anode separation for each machine line in output header :

IEO

- flag returned by user to indicate whether data is to be copled to tape.

ISTAT

- status returned from subroutines to indicate whether program should Immediately exit.

$\operatorname{EHDR}(4,80) \quad$ - array containing output header.

XZ

- record Immediately preceding the first output header array

LBD name record for the machine to be analyzed.

- location (record number) of $\dot{B}$ array on disc passed to subroutines.

LBDS

- saved location of $\dot{B}$ array on disc.

LBO

- IIne number in output header immediately preceeding the first line of array names, STATUS and PARl.

LCMP

- PAR1 value for first current monitor.

LCV

- Location of corrected voltage array on disc passed to subroutines.

LCV1

- saved value of location of first line corrected voltage.

LCVS

- saved value of. LCV.

LCVR

- location of current monitor array on disc passed to subroutines.

LCVRS

- saved value of Inftial LCVR.

LVMI

- saved value of location of first line voltage. 
LINE

LOAD

LNA

LVM

LVMS

MACHNO

NBD

NBD1

$\operatorname{NDI}(4)$

NSH(4)

$\operatorname{NVDI}(4)$

$\operatorname{NTB}(4)$

$\operatorname{NXR}(4)$

NUS

SHOT (4)

$\operatorname{USER}(4)$
- machine line number currently being processed.

- variable that keeps track of which overlay was loaded last.

- pointer to first two ASCII characters for each line in SHOT and USER.

- location of voltage monitor on disc passed to subroutines.

- saved value of LVM.

- machine number currently being processed.

- number of $B$ monitors on line being processed.

- saved number of $\dot{B}$ monitors on first line.

- ASCII name of CDIODE overlay.

- ASCII name of CSTHORT overlay.

- ASCII name of overlay VDICM.

- ASCII name of overlay TPBTVI

- ASCII name of $\mathrm{x}$-ray signal analysis overlay.

- counter of number of lines in use.

- ASCII characters containing output header SHOT entries for both lines..

- ASCII characters containing output header USER entries for both Iines.

\subsection{Overlay VDICM}

IDOT

IE

ISTAT

IV

IVST

KHDR
- flag that says whether a monitor is a differentiating type or not.

- end count for comparison.

- program status returned by user.

- counter in DO loops that process different monitors.

- STATUS entry for monitor currently. under consideration.

- output header. 


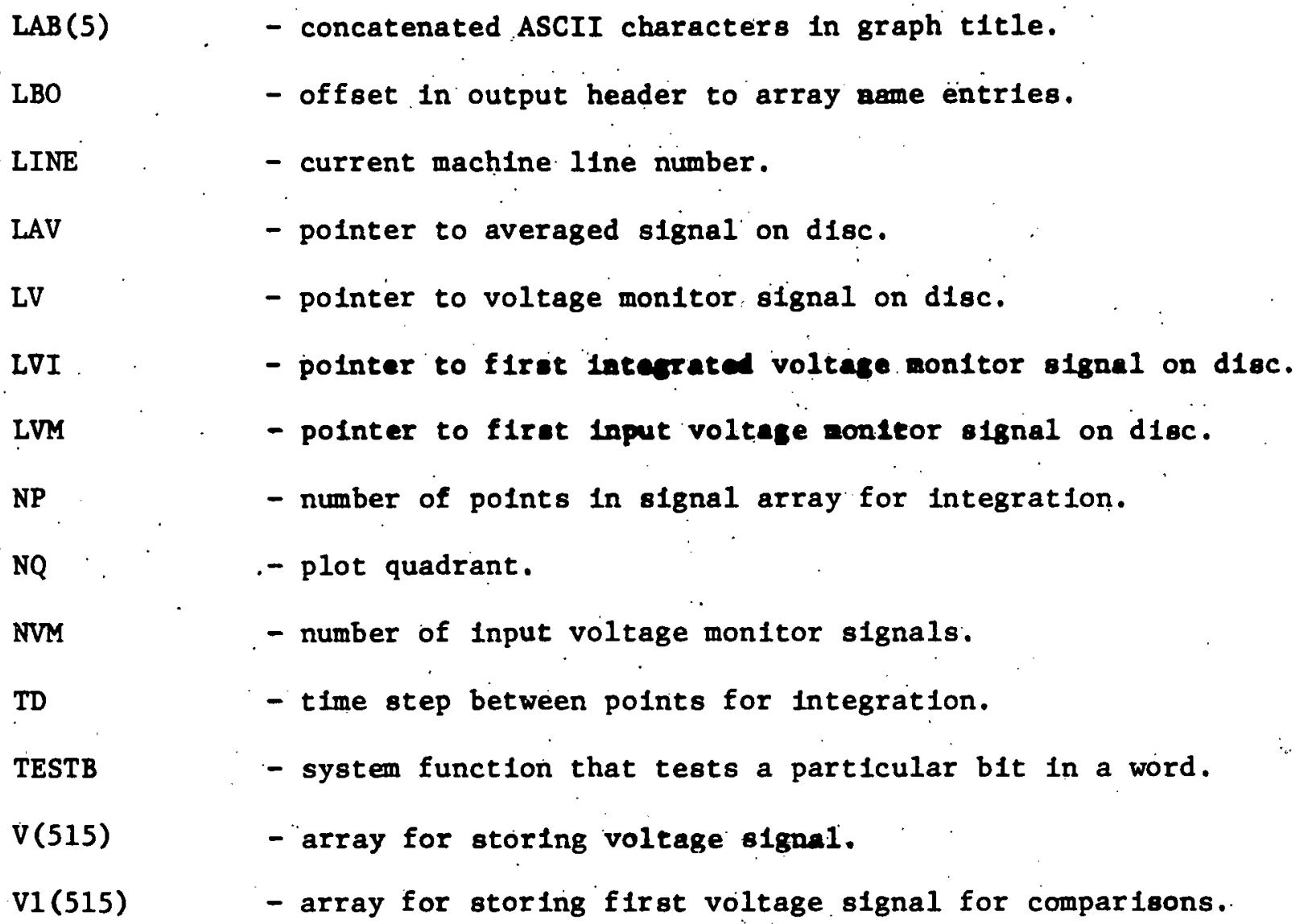




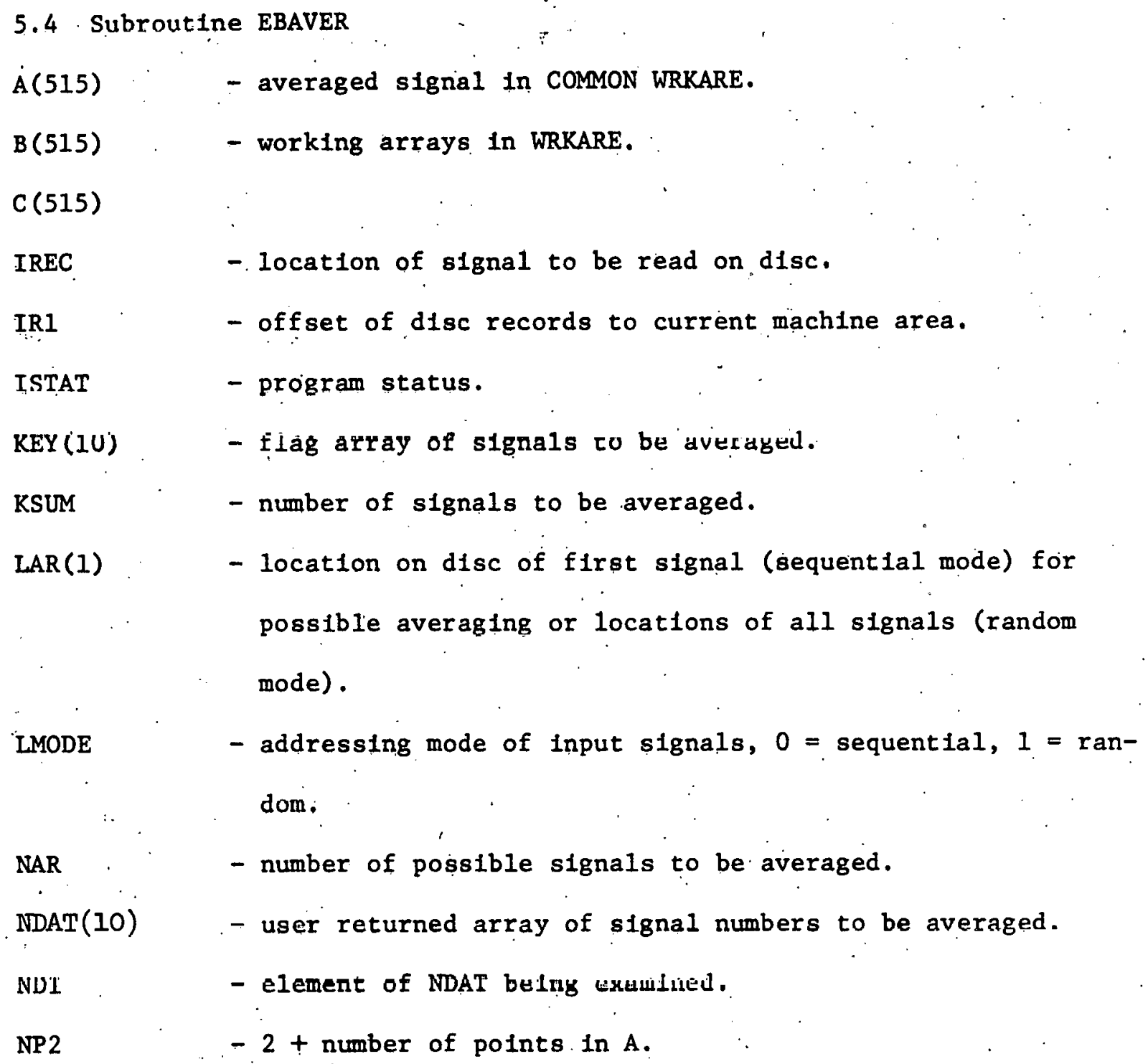




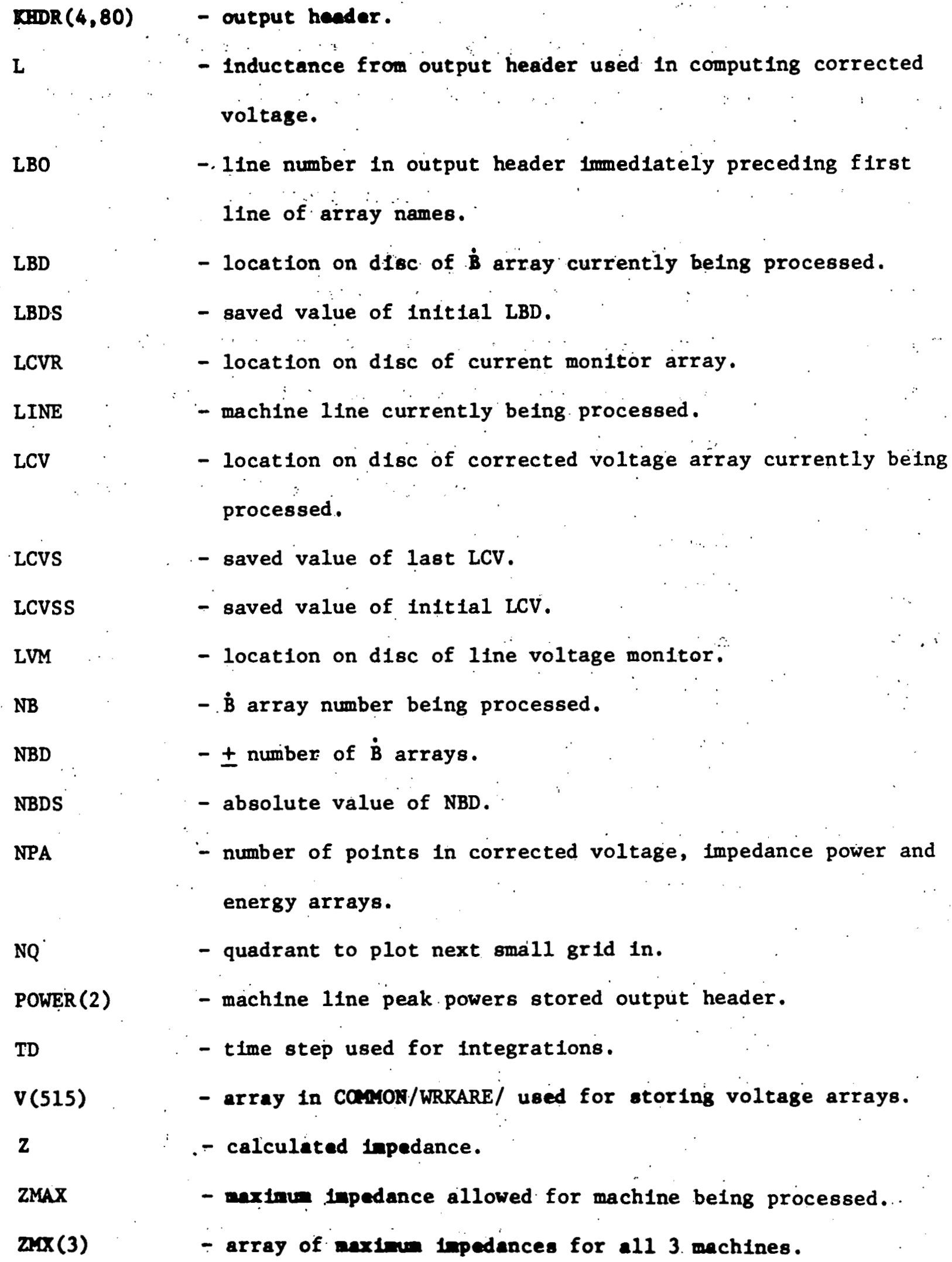




\subsection{Subrout1ne BDINPL}

$A^{\prime}(515) \quad$ - array in Carion/hrKare/ used to save $\dot{B}$ signal

$\mathrm{BD}(515)$ - array in COMMON/WRKARE/ used to store $\dot{\mathrm{B}}$ and Integrated $\dot{\mathrm{B}}$ signals:

IB

- disc record location of $\dot{B}$ being processed.

IST

- Integration subroutine status.

ISTAT

- subroutine status returned by user.

KAR

- ASCII Character used to label curves on large plots.

$\operatorname{LAB}(4)$

- concatenated graph.title for integrated $\dot{B}$ plot.

LBO

- output header array name off set.

LIB

- line number in output header of $\dot{B}$ name currently being processed.

NBD

- PARl entry for first line $\dot{B}$.

NBDD

- number of $\dot{B}$ monttors on line.

NBM1

- NBDD -.1

NP

- number of points in $\dot{B}$ array.

TD

- time step between $\dot{B}$ points;

5.7 Subroutine BDTAV

BD (515) - array in COMMON/WRKARE/ USED FOR STORING $\dot{\mathrm{B}}$ arrays.

ISTAT , - user returned status.

LBO - location of line in output header preceeding first line of array names.

LBD

- location on disc of first $\dot{B}$.

LCV

- location of first line corrected voltage array.

NBD

- number of $\dot{B}$ arrays.

NQ

- quadrant in. which to plot small grid. 


\subsection{Subroutine VIPLOT}

AI (515)

- array used for storling current array.

FFAC

- spacing between current points for constant Impedance and load line plots.

IGS

- flag to plot subroutines to treat first call argument as an array or a $\Delta t$.

ISTAT

- user returned status.

IV

- voltage value being claculated for constant impedance and load line plots.

IZ

- number of constant impedance line being computed.

LCV

- location on disc of voltage array.

M

- machine number +1 .

MACHNO

- machine number.

MV

- number of load line belng computed.

N

- number of points computed for constant impedance and load Iine plots.

NP

- minimum number of points in current and voltage arrays read off disc.

$\operatorname{VM}(4,3)$

- array of machine Marx voltages used in computing load lines.

VMM

- scaled Marx voltage:

XMAX

- number corresponding to right edge of plot grid computed by plot subroutine.

XMIN

- number corresponding to left edge of plot grid computed by plot subroutine.

$\mathrm{Z}(3,3)$

- impedances for all three machines used in computing constant impedance lines.

ZM(3)

- impedance for each machloe used in computing load lines. 


\subsection{Overlay CSHORT}

AAL

BD (515)

BDFAC

ISTAT

$\operatorname{KHDR}(4,80)$

LABT (3)

LBD

LBDS

LBO

LINE

LVM

NBD

NBDE

TSH

TSHIF

$\mathrm{U}(515)$

$V(515)$

VOLT (515)
- Inductance returned from voltage-B comparicon.

- array in COMMOND/WRKARE/ used for storing $\dot{B}$ signals.

- $\dot{B}$ calfbration factor returned from BDCAL subroutine.

- returned status.

- output header.

- array containing concatenated ASCII graph title for voltage - $\dot{B}$ comparison plot.

- location on disc of $\dot{B}$ currently belng processed.

- saved value of location of first $\dot{B}$ array.

- IIne number in output header of line preceding the first line of array names.

- location on disc of current monitor array.

- machine line currently being processed.

- location on disc of voltage monitor array.

- \pm number of $\dot{\mathrm{B}}$ monitors used.

- abeolute value of NBD.

- tIme shift returned by BDCAL subroutine.

- time shift returned from voltage - $\dot{B}$ comparison.

- arrays in COMMON/WRKARE/ used as working arrays in voltage - $\dot{B}$ comparison.

- array in COMMON/WRKARE/ used to store voltage monitor slgnal.

5.10 Subroutine BDCAL

BD (515)

- array in COMMON/WRKARE/ used for storing $\dot{B}$ array.

BDFAC

- $\dot{B}$ callbration factor.

CVR (515) 

aв a delta $x$.

ISTAT

$\mathrm{R}$

$\operatorname{KHDR}(4,80)$

LABT (7)

LBD

LCVR

LI

NPTS

TD

Tsì

$v(515)$

$\mathrm{U}(515)$
- user returned program status.

- location of last data point in B array.

- output header.

- concatenated ASCII characters used as graph title for current monitor - Integrated B comparison.

- location on disc of $\dot{B}$ array.

- location on disc of current monitor array.

- number of first line of array names in output header.

- number of points in $\ddot{B}^{\prime \prime}$ array.

- time step between $\dot{B}$ signal points.

- time shift between current monitor and integrated $\dot{B}$ returned from comparison program.

- arrays in COMMON/WRKARE/ used as working arrays by comparison program.

\subsection{Overlay PIXCAI}

IE

- number of pin diodes.

$\mathrm{IM}$

- one less than number of pin signals.

INTS

- Integration status.

ISTAT

- user returned status.

JE

- number of comparisons for eachi pln dlode.

KHDR

- output header array.

KAR

- character used to label curves in overlay plot.

LABLOC

- pointer to array label in output header.

LABT

- graph title for comparison plots. 
- array naw offaet in output header.

LOCIN

- pointer to Input array on disc.

LOCOUT

- polnter to output array on d1sc.

LPWR

- pointer to power array on disc.

LXI

- pointer to first input array on disc.

LXO

- pointer to first output array on disc.

NP

- number of polnts in array.

PIN

- array for storing pin dlode signal.

POW

- 1, array for stor 1ng second pin signal in comparisons;

2. array for storling power signal.

TD

- time step between array points.

\subsection{COMMN Storage Areas}

The root program DID, the overlays, and the subroutines in the task use a number of labelled COMMON areas for storing data and passing arguments. Each COMON area is described below.

\subsubsection{COMMON/TAPES/ITST, IUTT (8), KHDR $(4,80)$}

This common area is used by the magnetic tape storage subroutines and all suboroutines that produce plots. It is also used to store the output header.

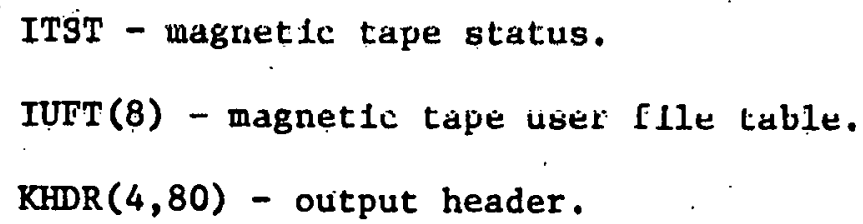

5.12 .2 COMMON/WRKARE/A (515), B(515), C (515), D(515)

All four arrays in this comion area are used as working data arrays In computing varlous machine parameters. The individual subprograms label the arrays differently, but they st11l use the same area of core. 
5.12.3 COMON/GLOCOM/YSH, MAY, MS, IPR, IOP1, IOP2, IDAST (38)

This COMMON is global to the computer operating system. Th1s means all properly edited jobs and tasks have access to 1t. It occuples fixed absolute core locations \#FFO0 - \#FF2C. It is used for passing 1nformation among different tasks.

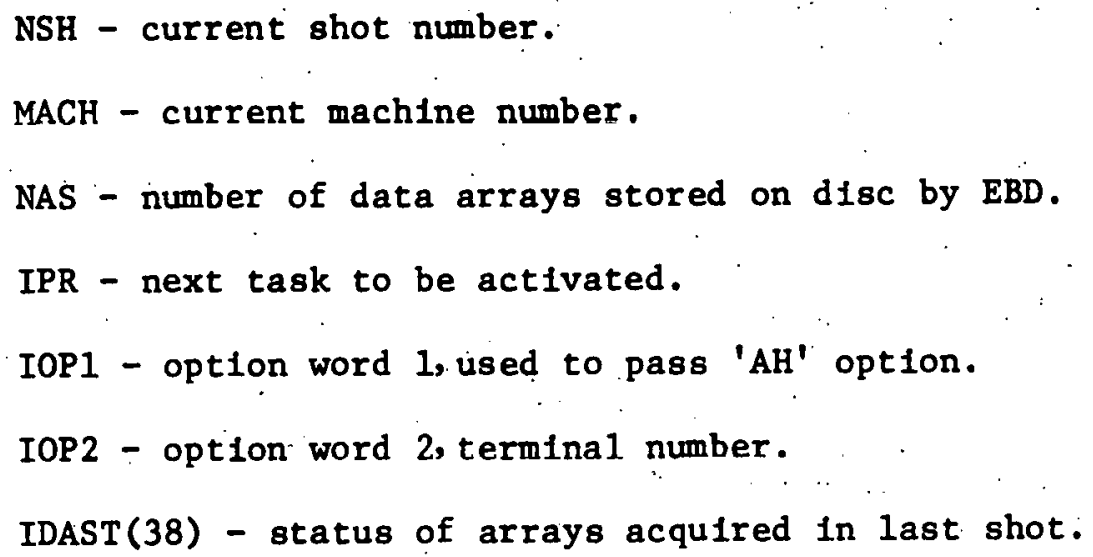

5.12. 4 COMMON/MGLCOM/NSHOT, MACHNO, NARAYS, IPRST, IHDR, ITRM, KZ, NUS (5)

This common area is used to store the critical parameters passed to the program in the global common area GLOCOM. This 18 necessary since. other programs could change the or 1 ginal contents of GLOCOM while a DIODE is running.

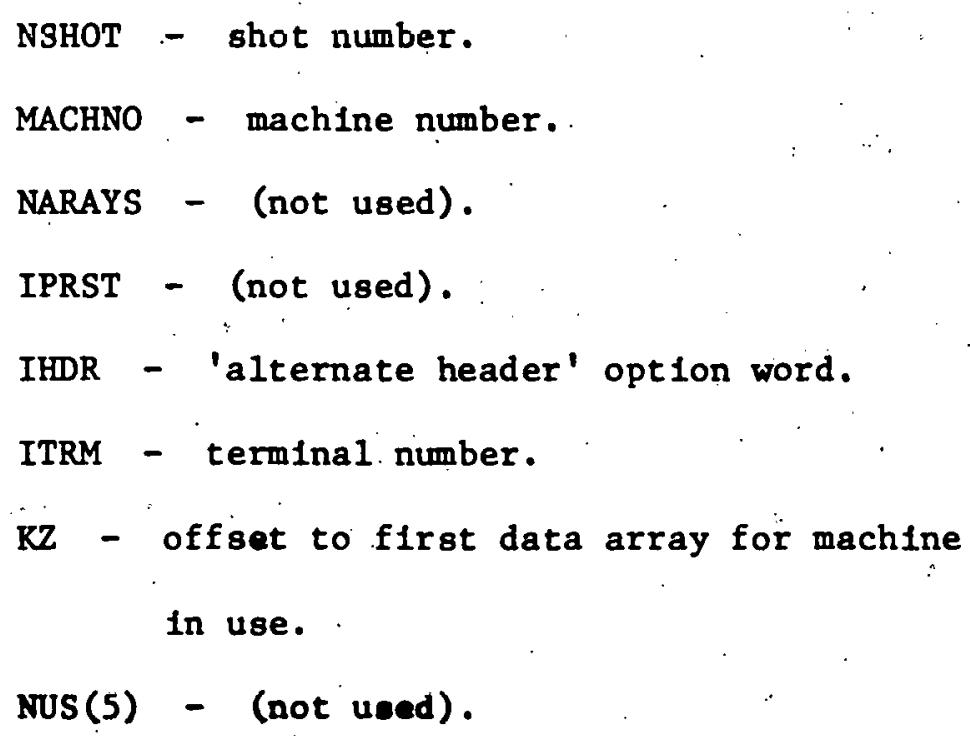




\subsection{2 .5 COMAON/DAIOV/I22, I23, I21, I20}

This comon area contalns the 'assoclated varlables' for direct access disc files $22,23,21$, and 20 respectively. ${ }^{3}$

\section{Flow Charts}

The following sections contain flow charts for the major programs in the DIODE task. The symbols used have the following meaning:

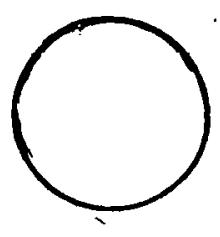

statement number

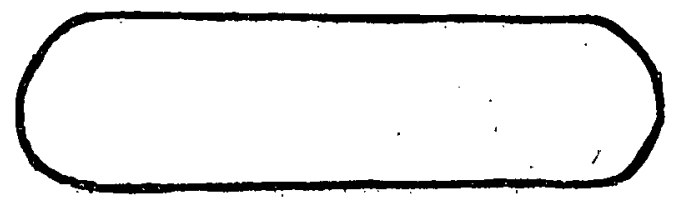

decision to be made

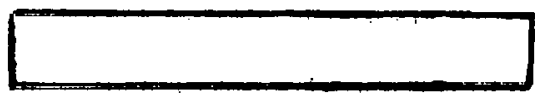

arithmotic operation

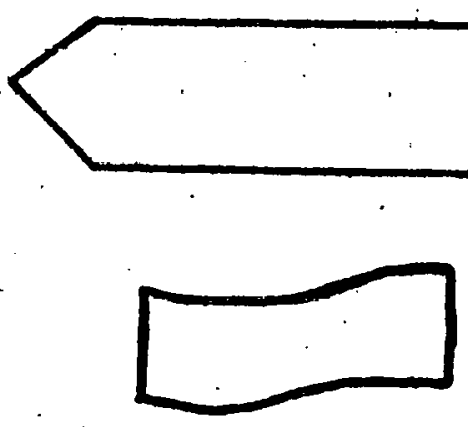

subroutine call

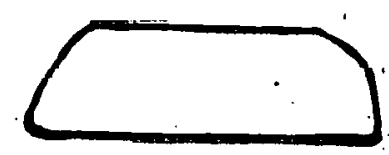

comment

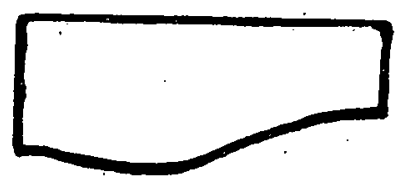

program name

Input/output operation

- return from subroutine 
6.1 DIODEp - control prosren

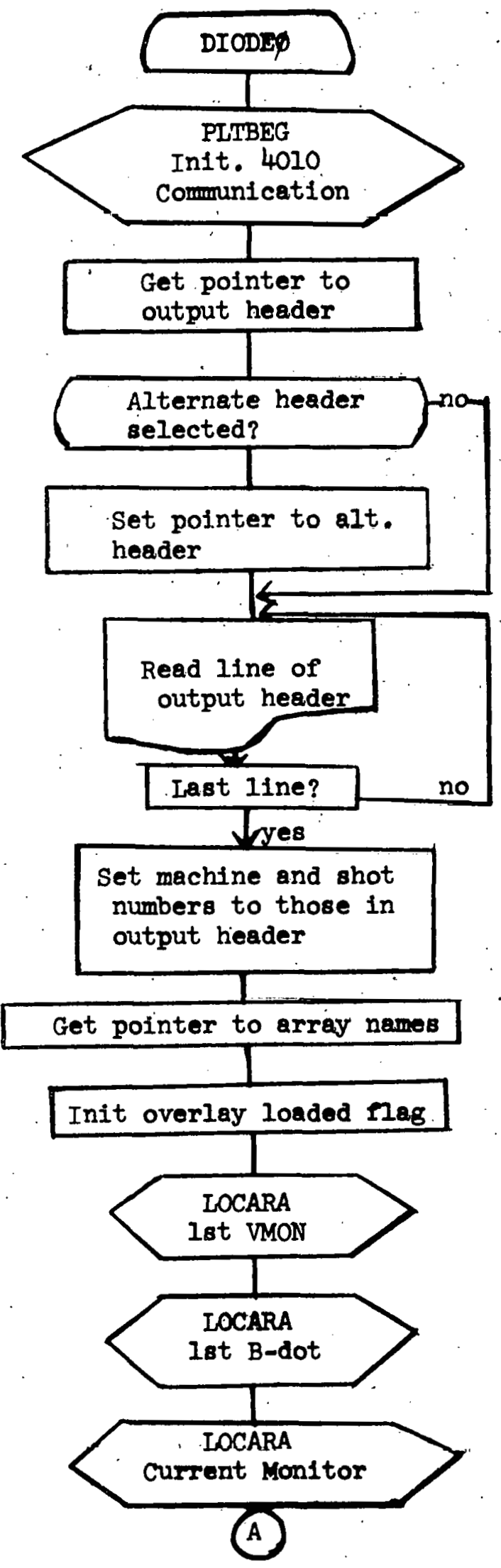

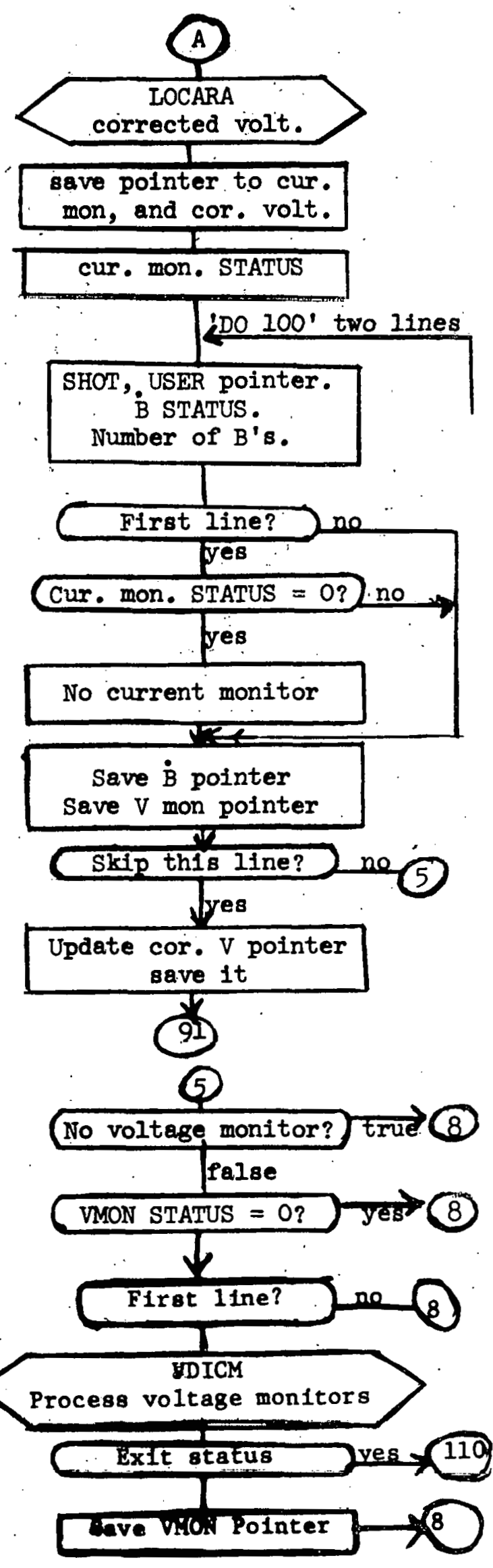


8

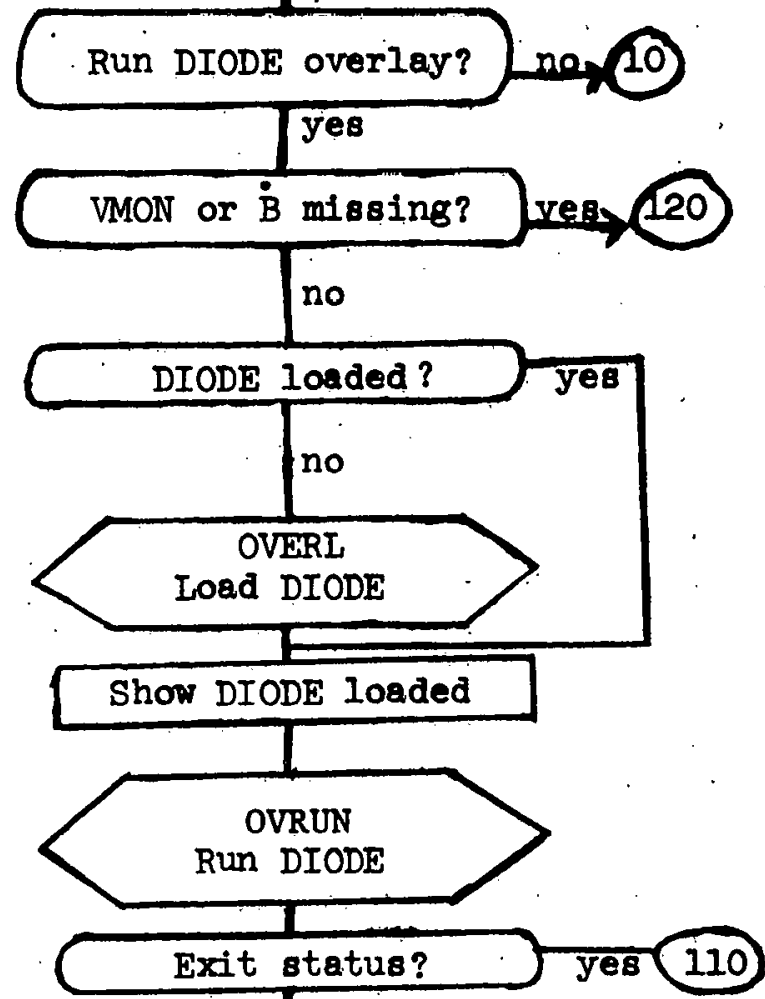

no

Restore VMON pointer

Restore $B$ pointer

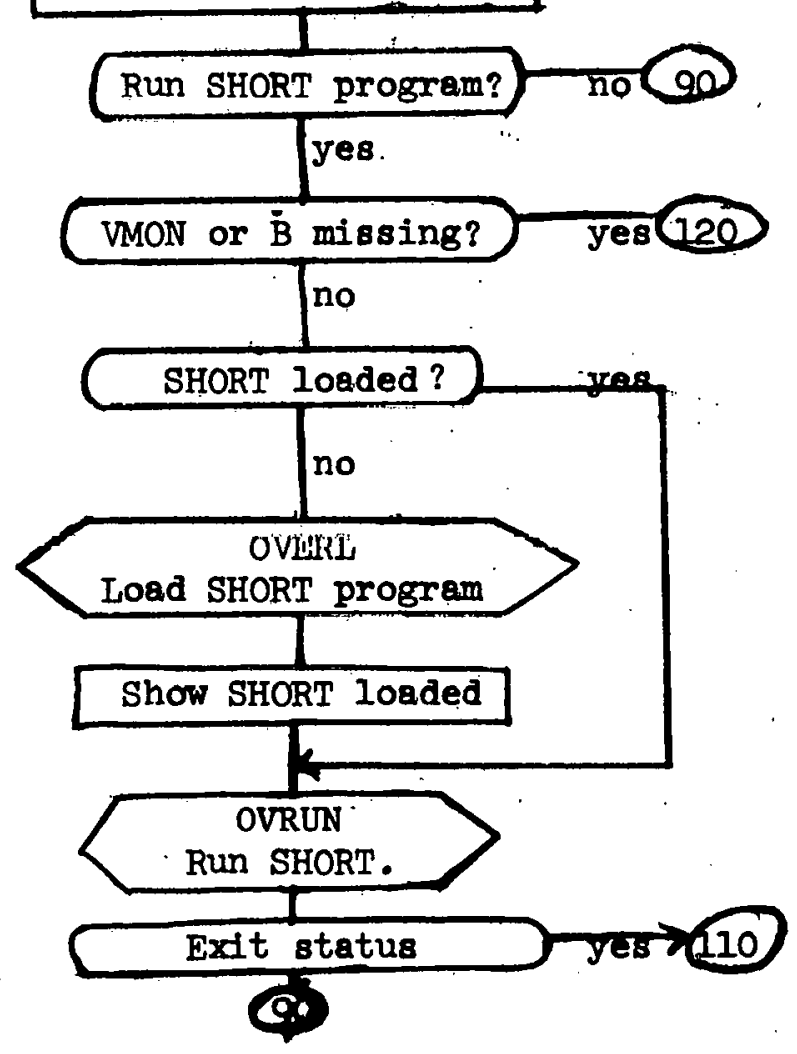

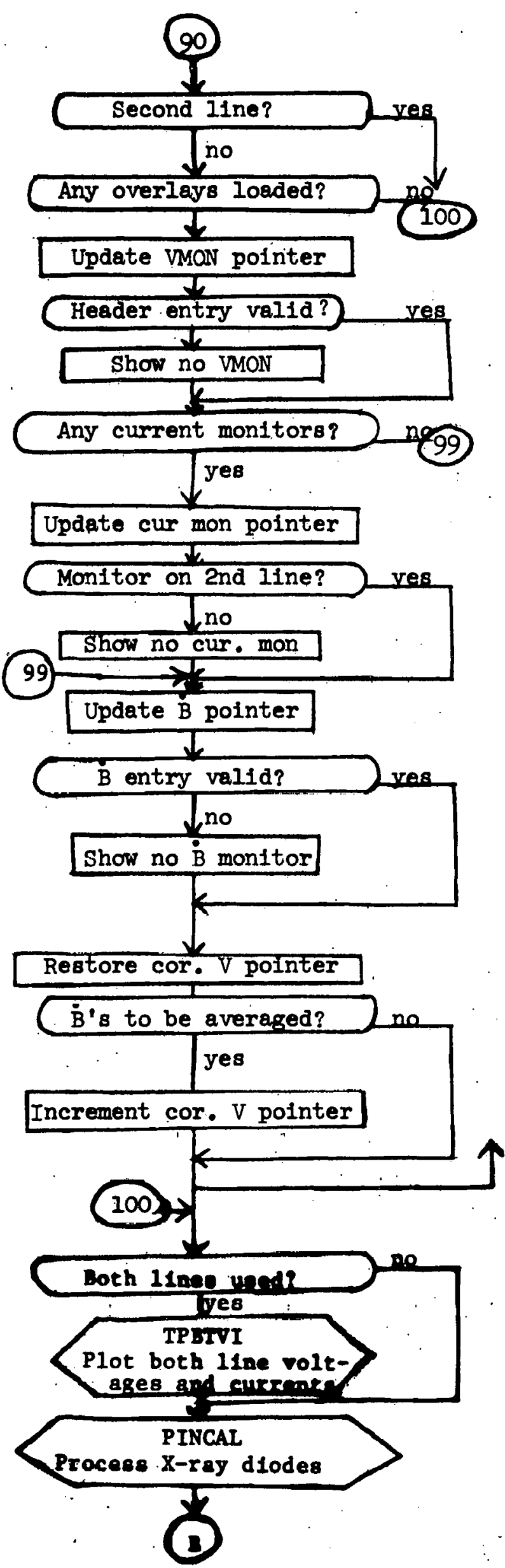




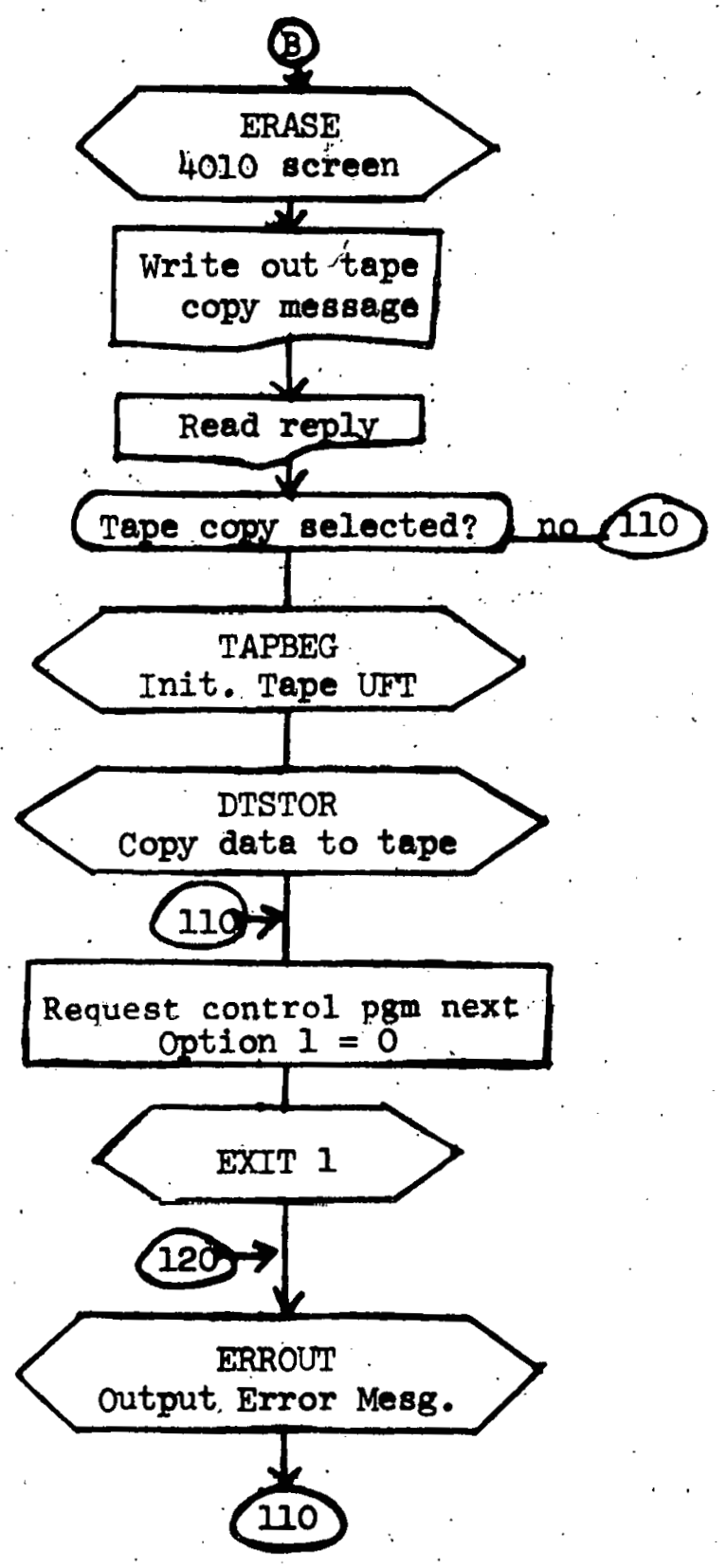


6.2 Overlay VDICM - process multiple or integratin. (A)

\section{VDIOM}

offset for array names.

Init plot quadrant. Number of VMON's.

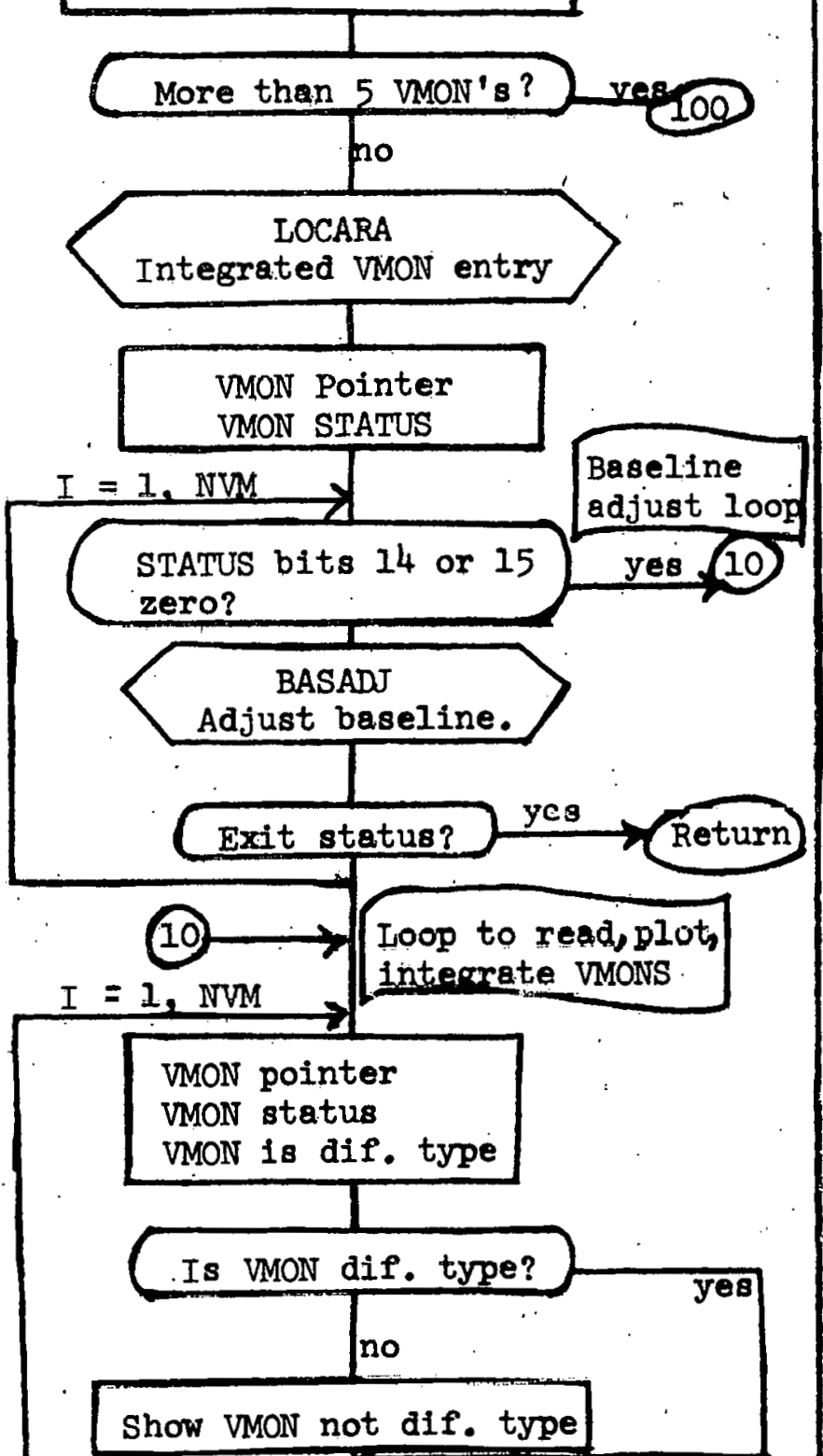

Show VMON not dif. type

Read VMON from

disc

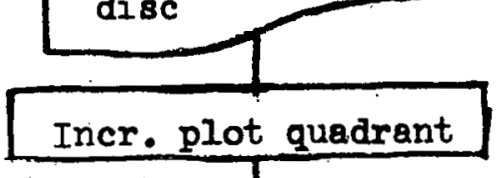

EBPLT4

Plot VMON
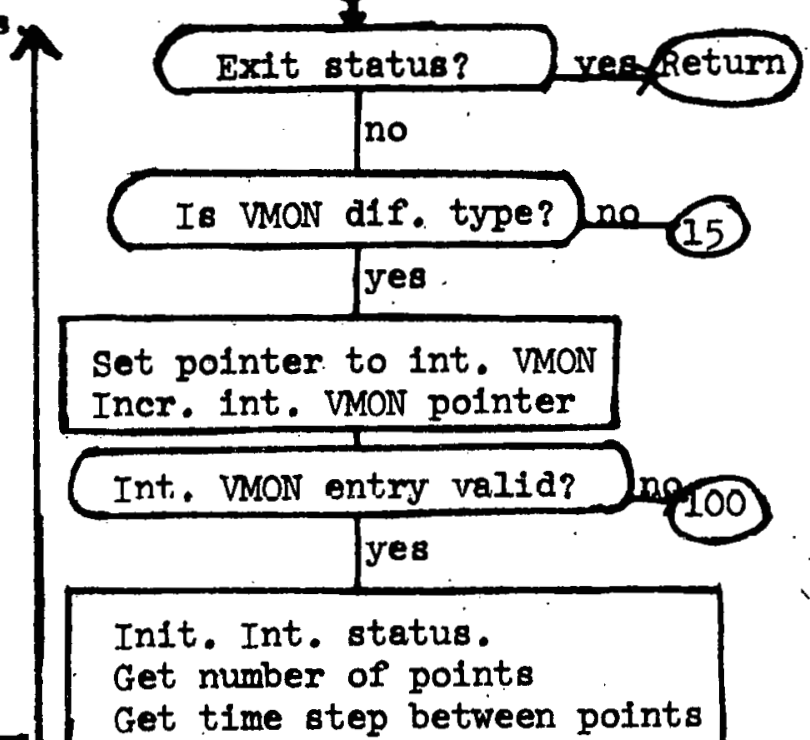

Set pointer to int. VMON Iner. int. VMON pointer

Int. VMON entry valid? yes

Init. Int. status.

Get number of points

Get time step between points

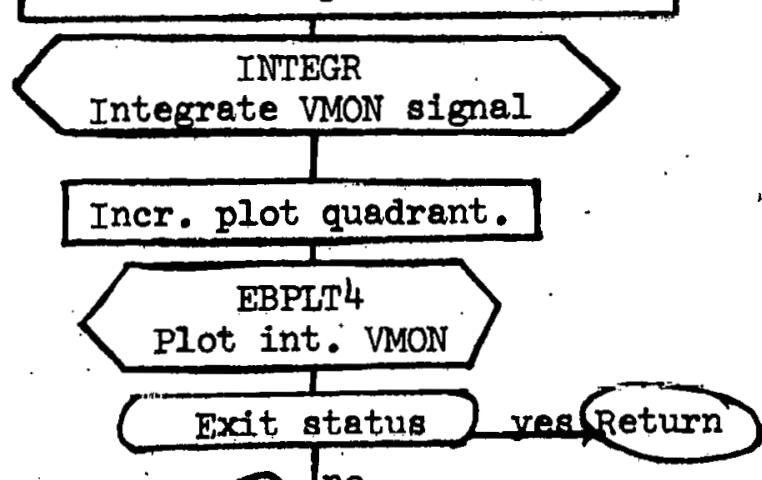

15. no

First VMaN?

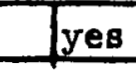

(19)

100

\section{(}




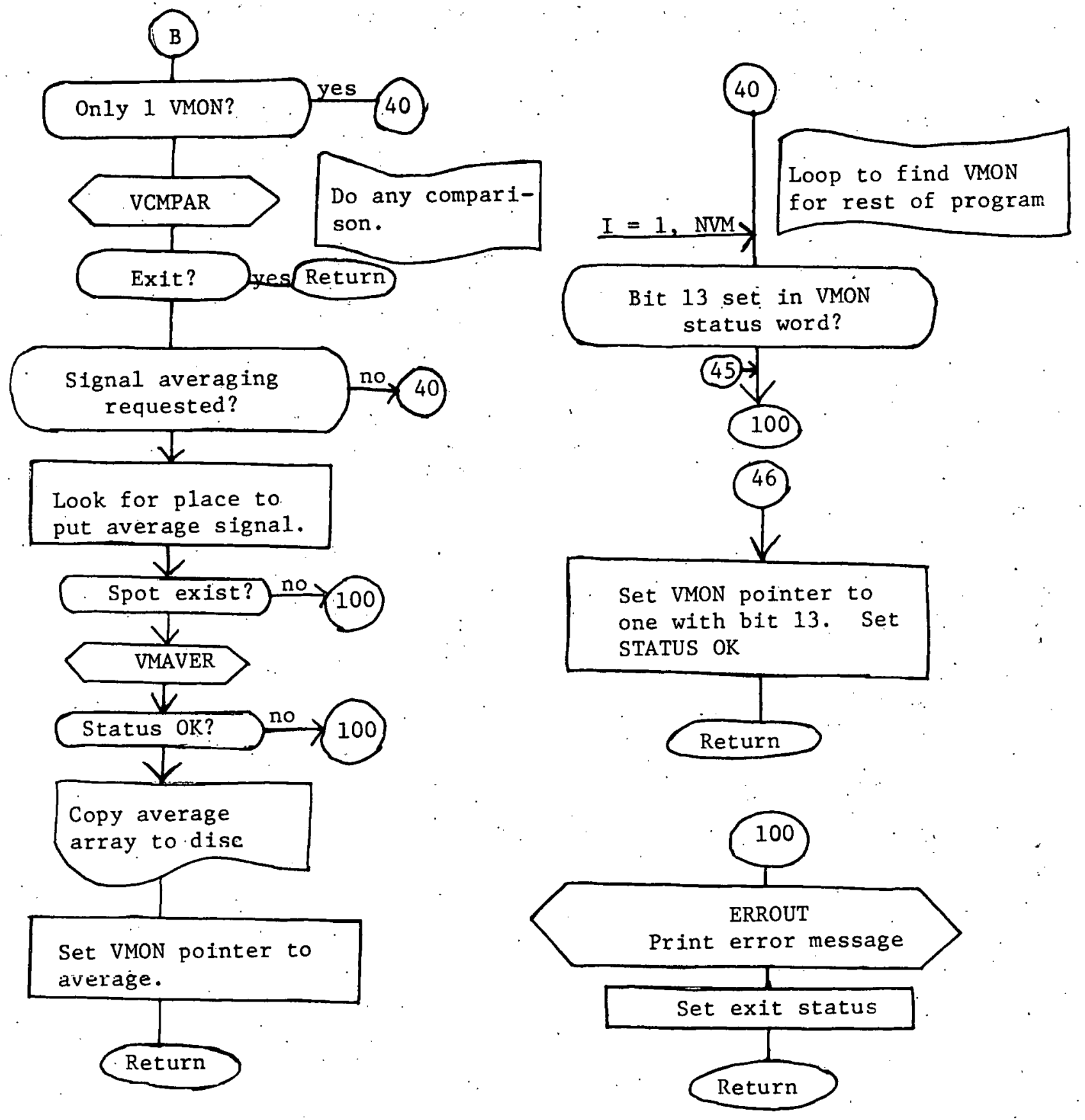




\subsection{Subroutine BASAD - manuilly adjust arrey babeline for Integration}
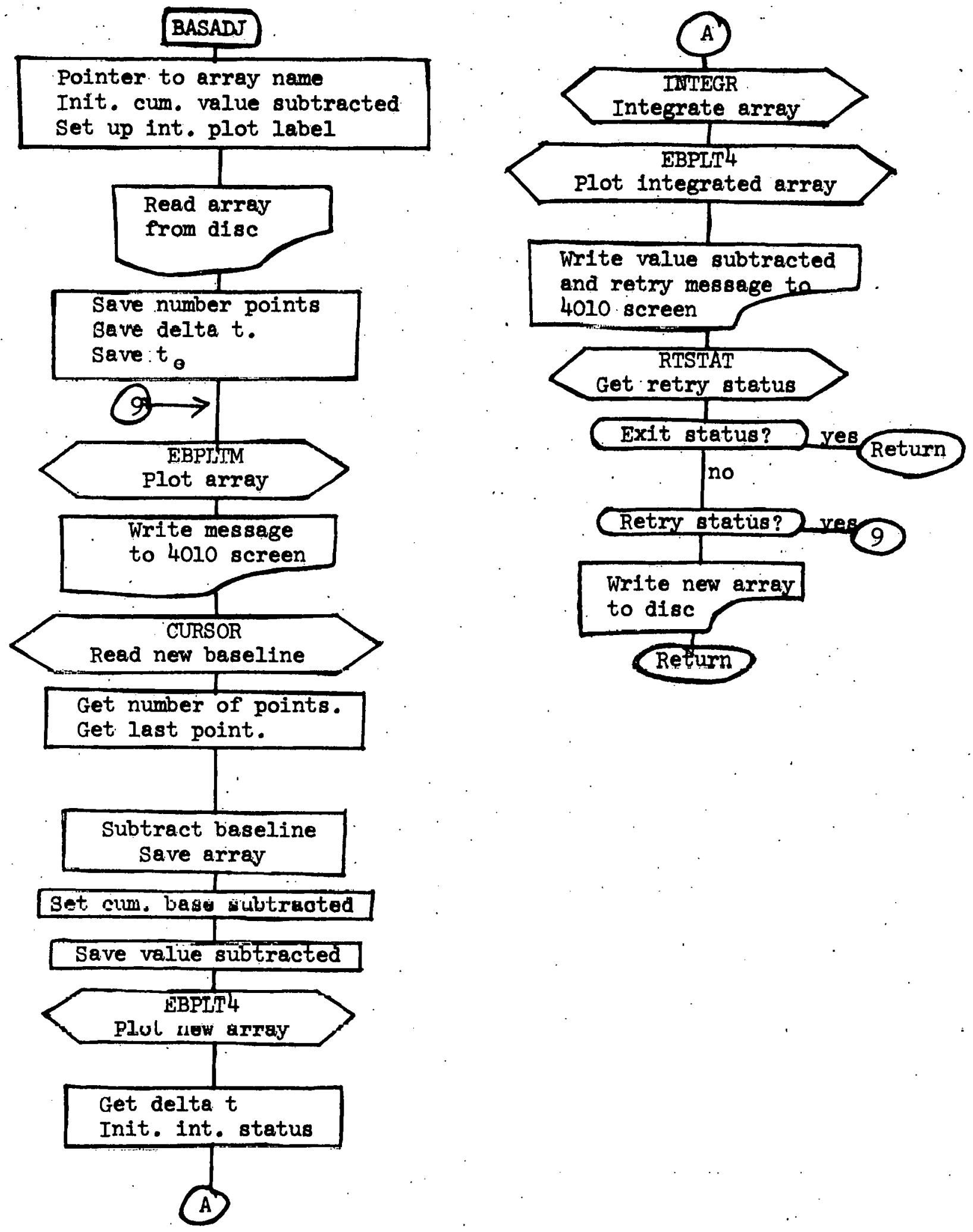

Pointer to array name

Init. cum. value subtracted

set up int. plot label

\section{Read array \\ from disc}

Save number points

Geve delta $t$

$t_{0}$

EBPITTM

Write message

to 4010 screen

\section{CURSOR}

Read new baseline

Get number of points.

Get last point.

Subtract baseline Save array

Set cum, base subtraoted

Save value subtracted

BPLT

rray

Get delta $t$

A 
6.4 Ovérlay VCMPAR - compare voltage monitors.

\section{VCMPAR}

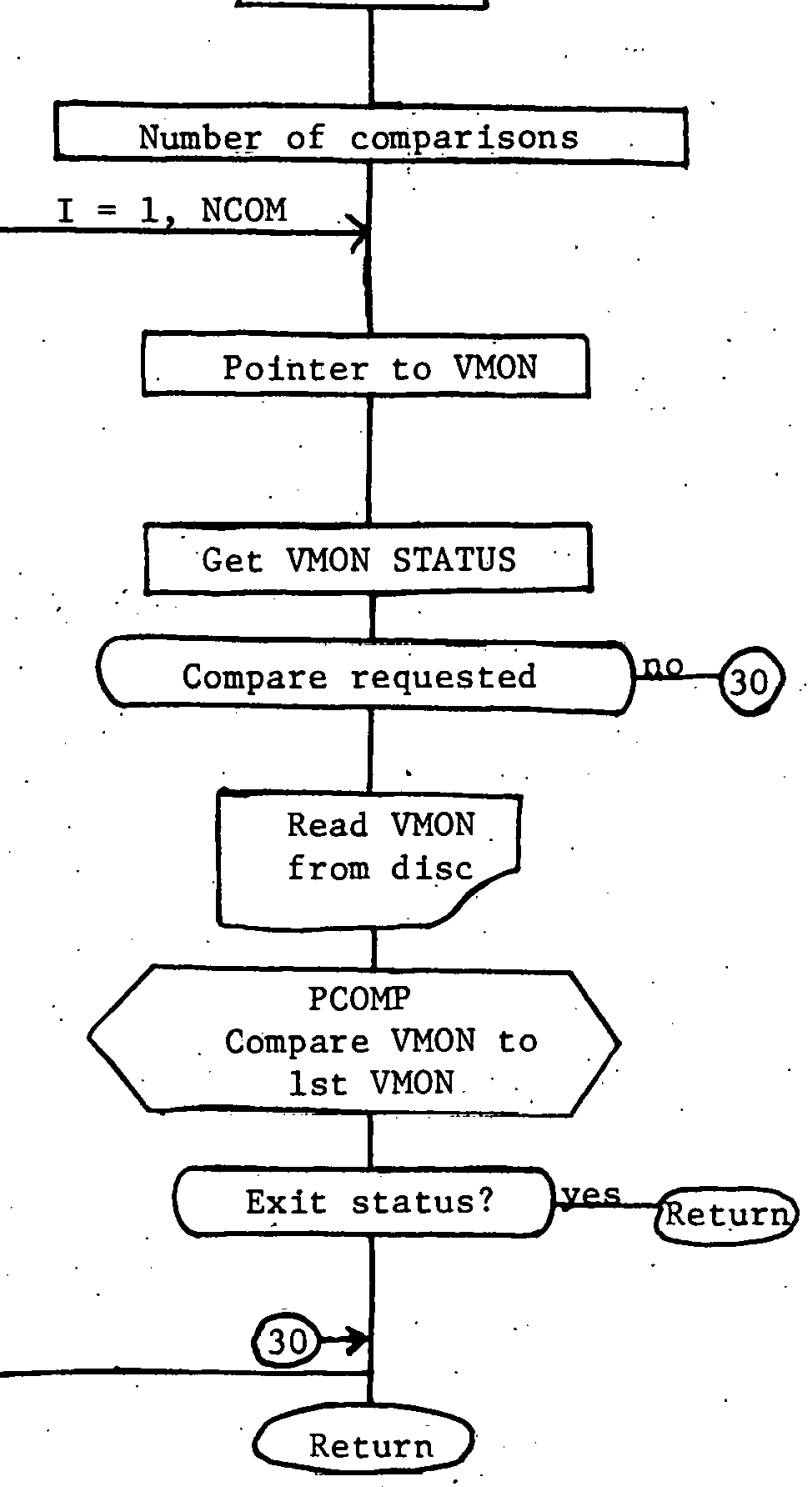

6.5 Overlay VMAVER - Call subroutine to average voltage monitor signals.

0

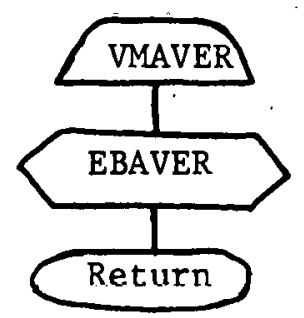




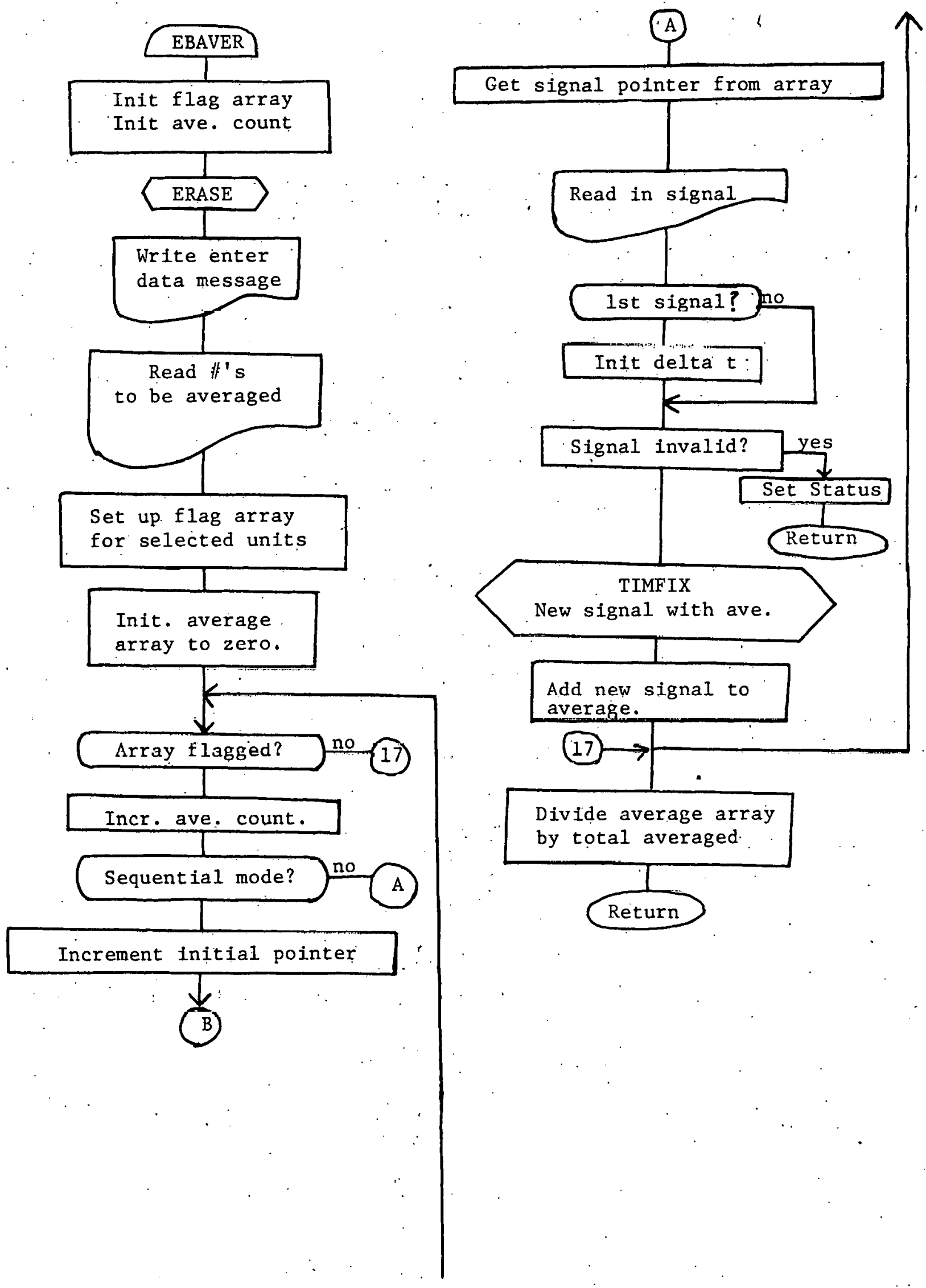




\section{2 orerlay CDIODS + compute diode parformace parcatare,}
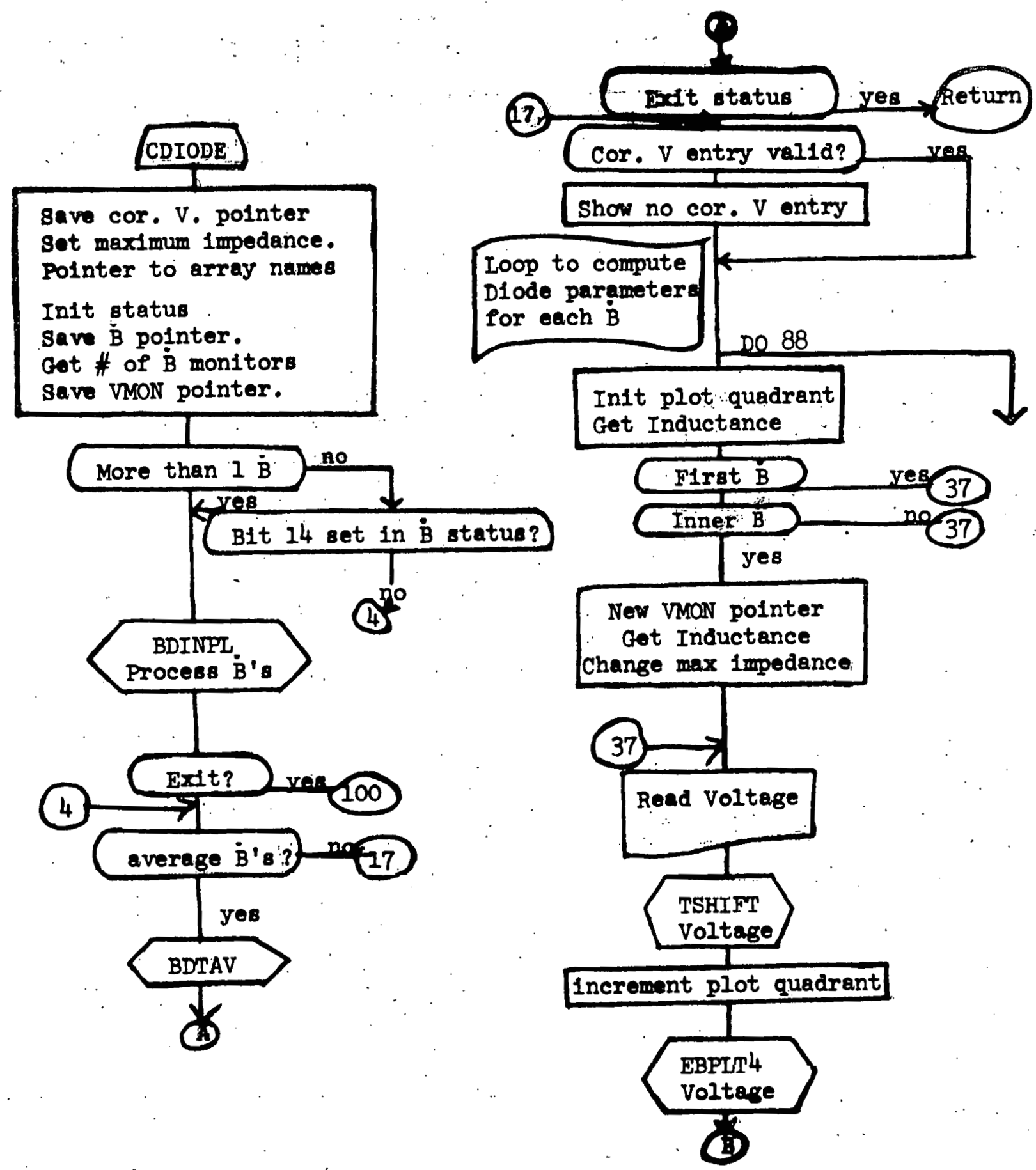


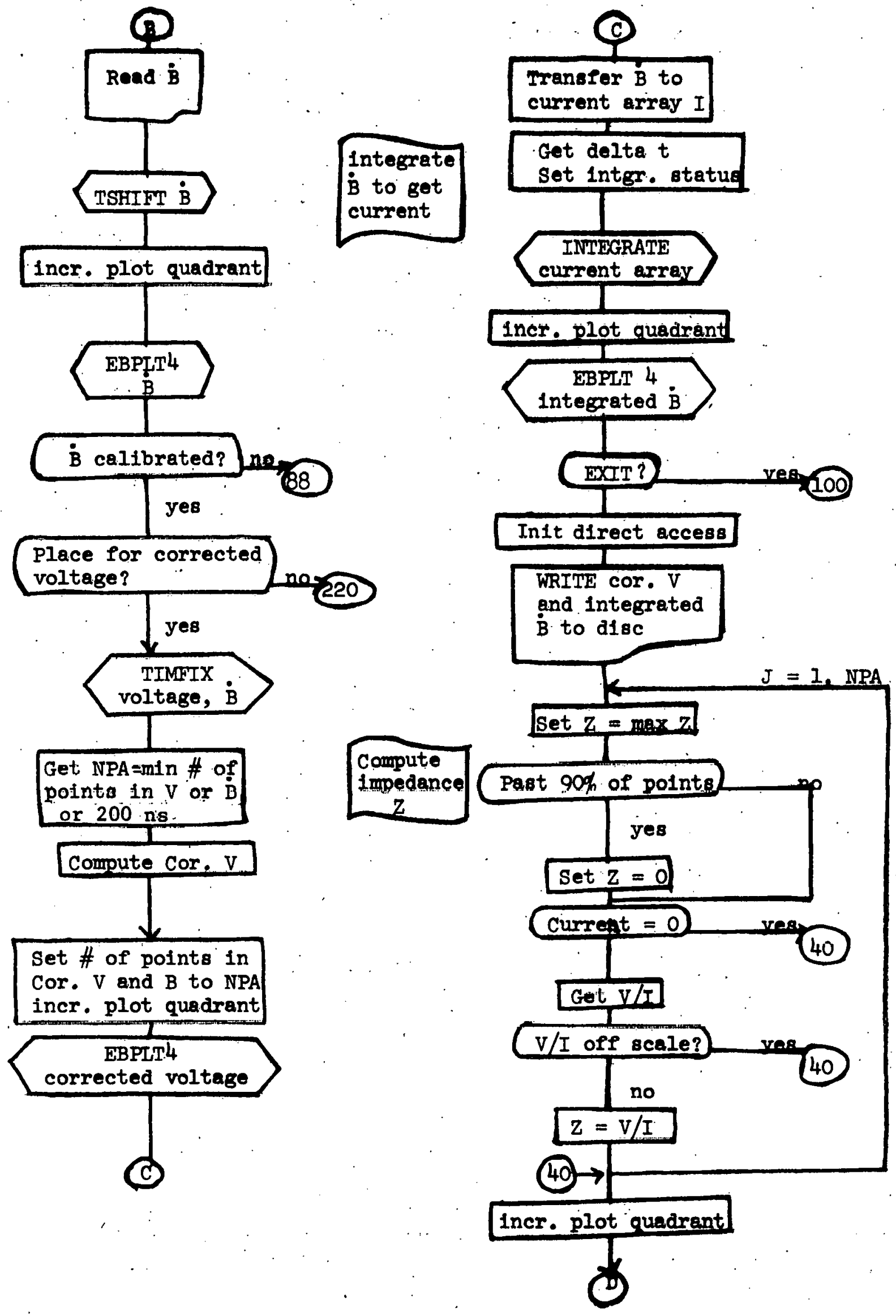




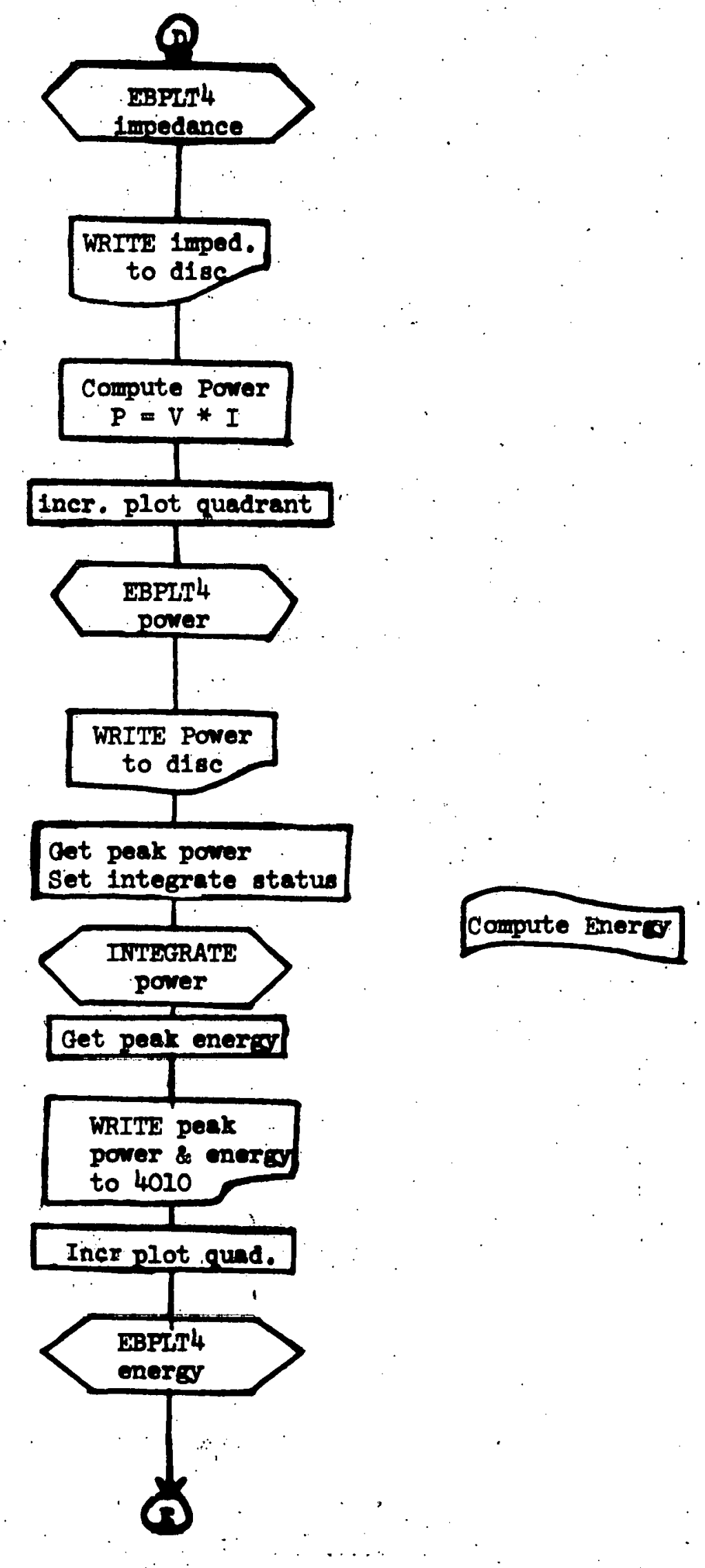




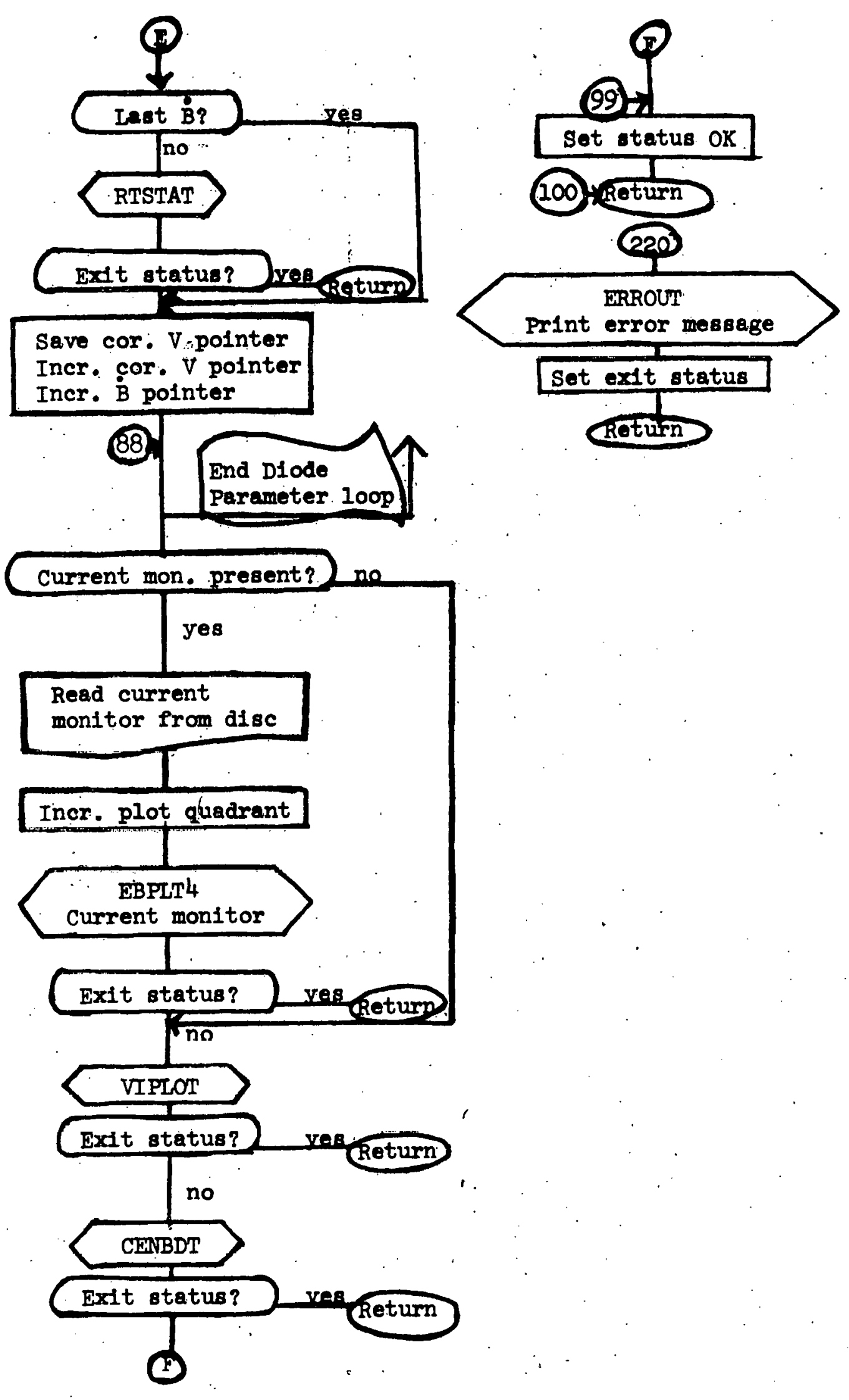

54 


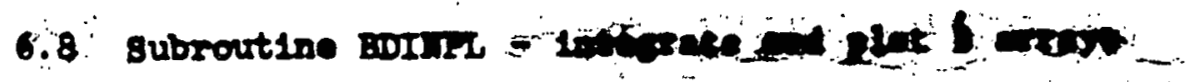

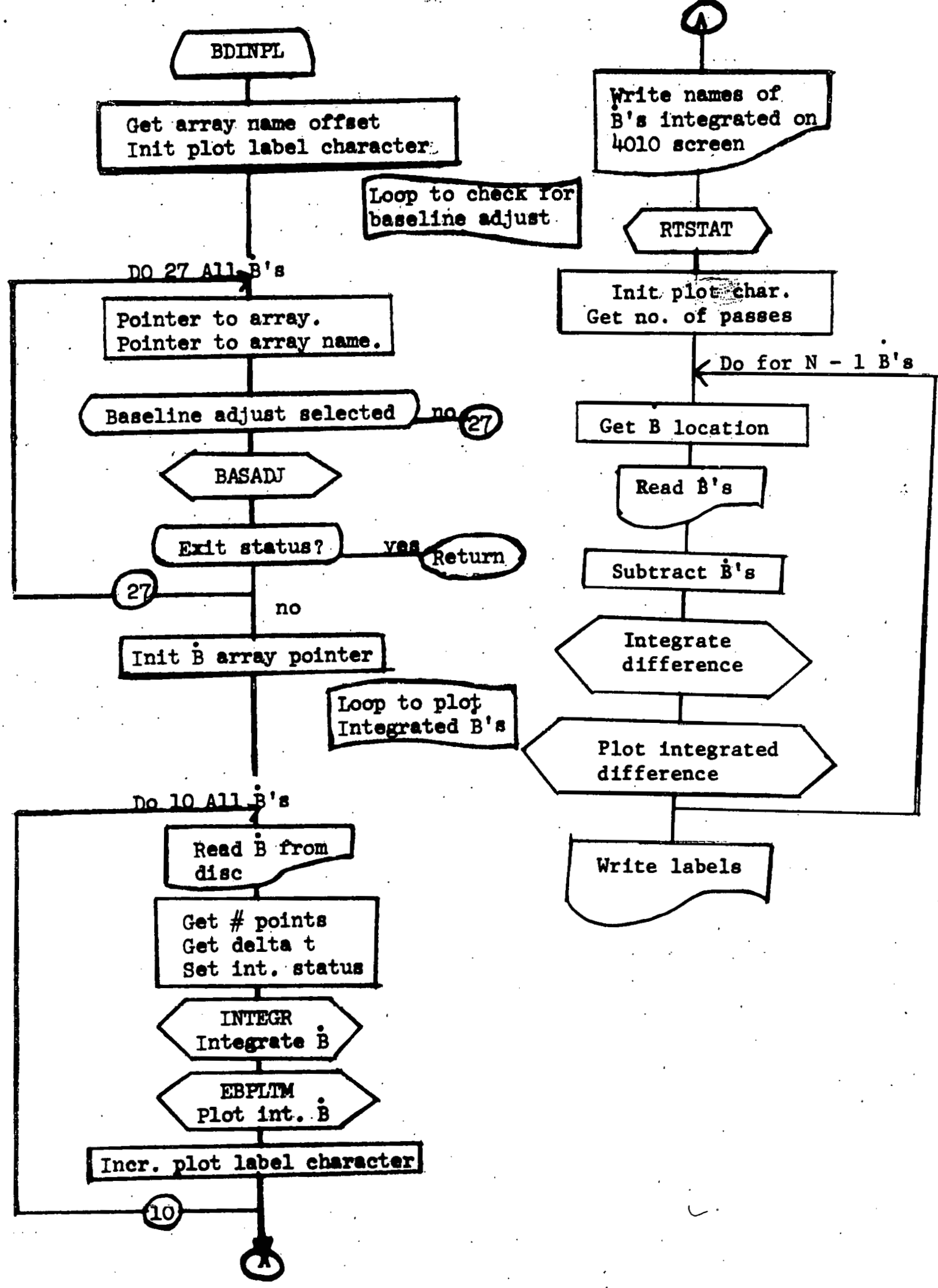


6.9 Subroutine BDTAV - average $\dot{B}$. signal.

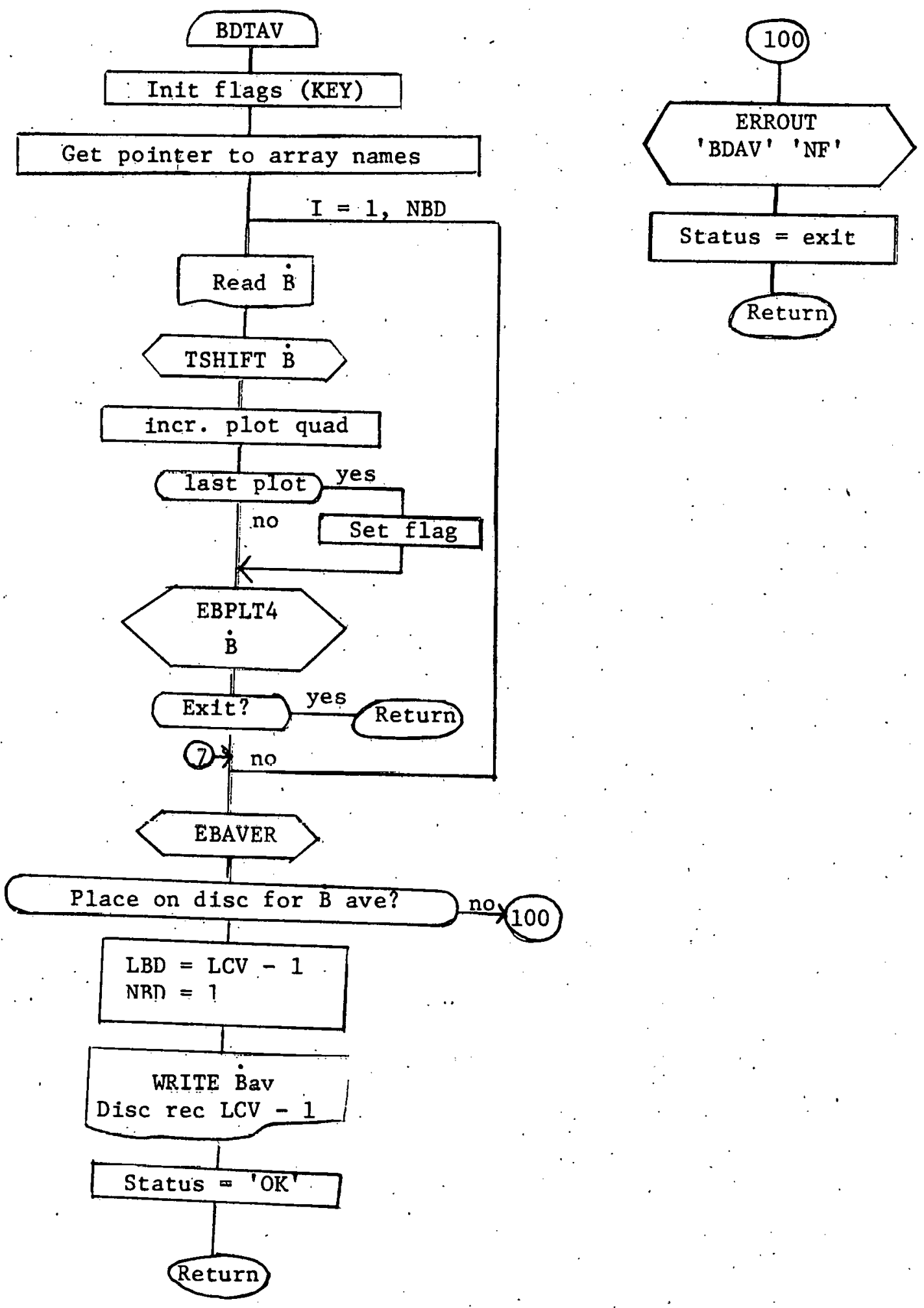




\subsection{Subroutine VIPLor - plot voltege ve currat.}

VIFLOT

Set mach pointer $(M)$

set \# points (N)

READ voltage

Disc rec. IC

READ current

Disc. rec. LCV +1

Set graph mode
GRAPHE

volt., current

current step (FFAC)

Make current array

$\angle I=1.3$

\section{yake $V$ array for $\mathrm{Z}$ (IZ)}

Set graph mode

PLOT constant Z(IZ)

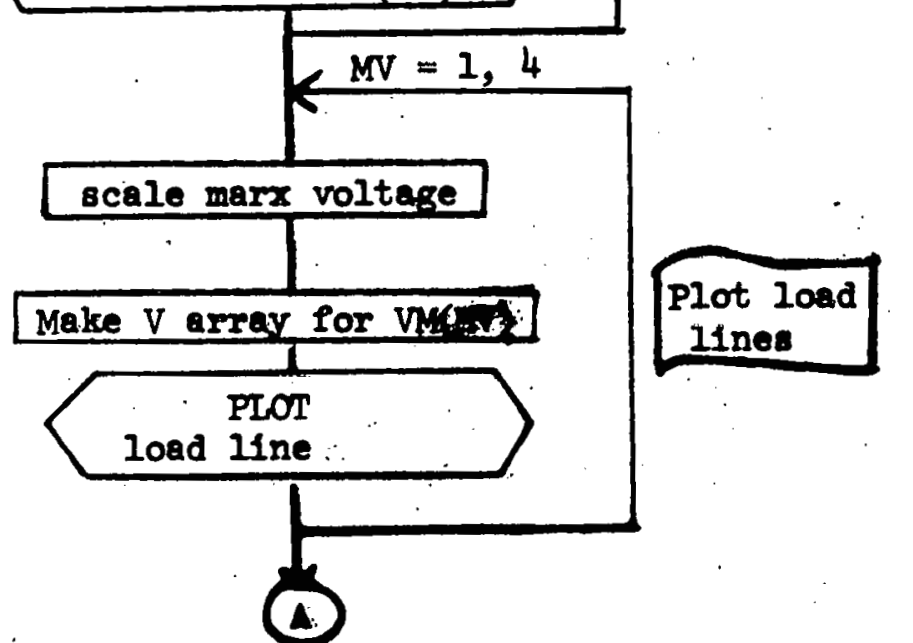

Plot cor. V ve Int $B$
Plot constant

Zines
RESET

SHOTWR

WRITE

$\mathrm{Z}^{\prime} \mathrm{s}$ and $\mathrm{VM} \cdot \mathrm{s}$

in overlay plgtn

RTSTAT

Return 
6.11 Overlay CSHORT - nakes short circult shot compar1sons:
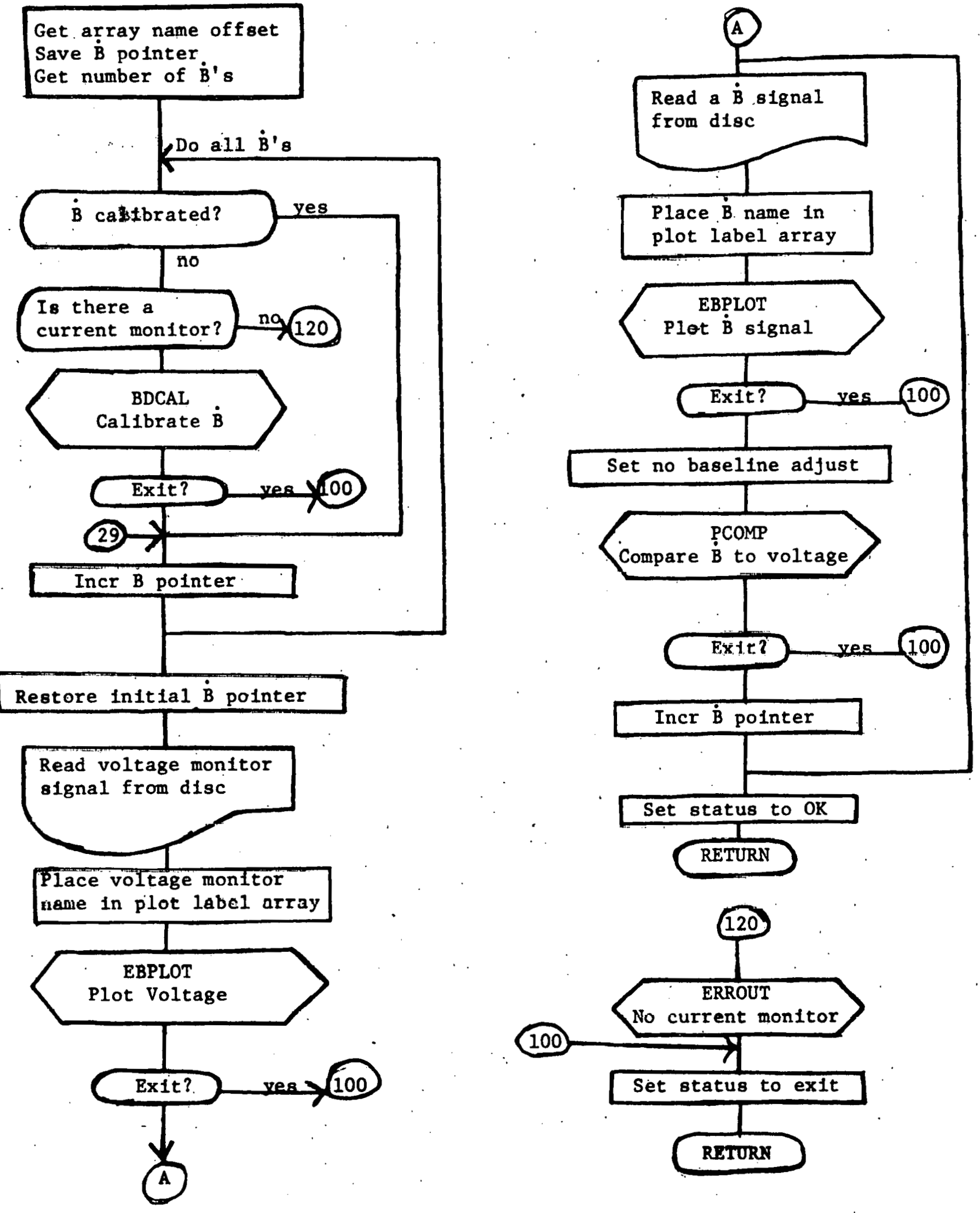
6.12 subyoutine BDCAL-caltbrate $\dot{B}$ s1gnal with optlonal baneline adfust

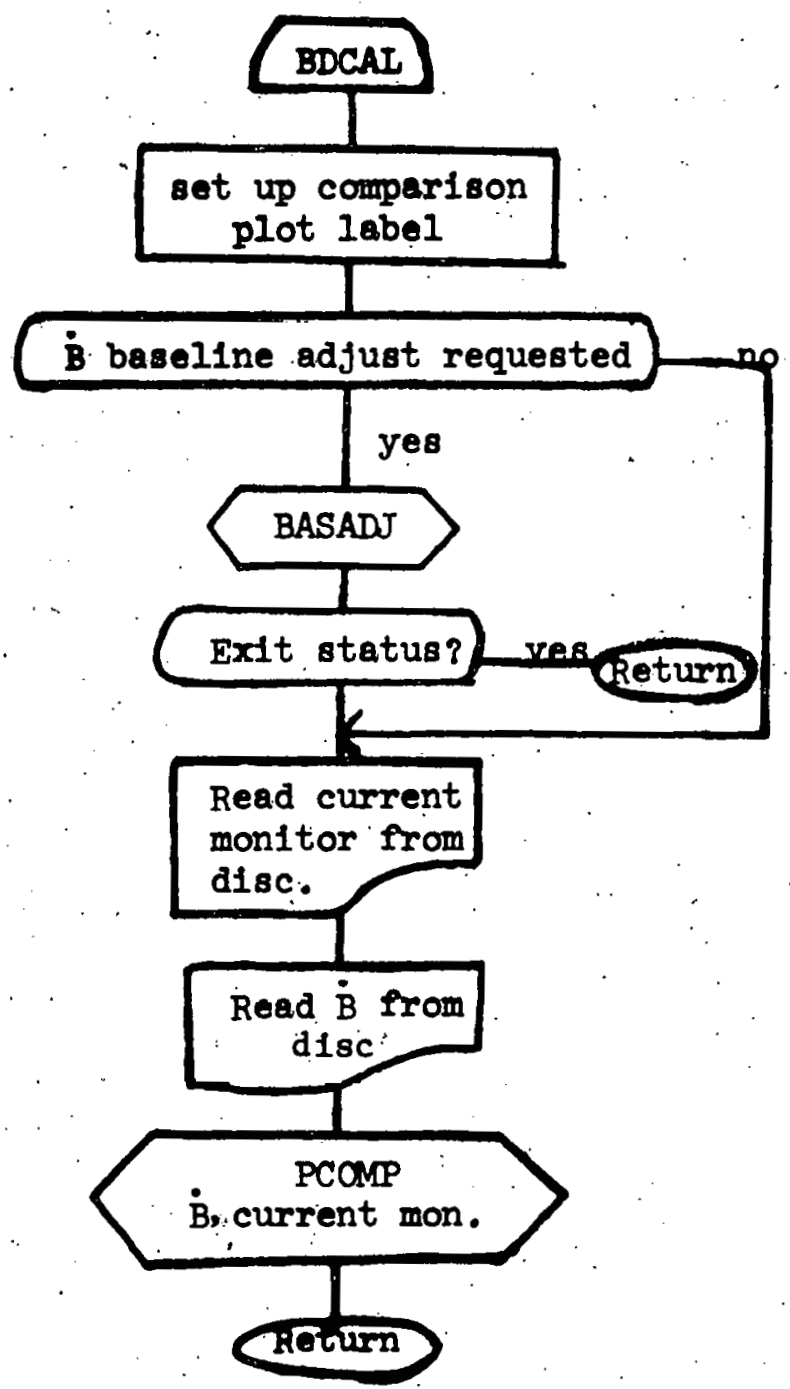



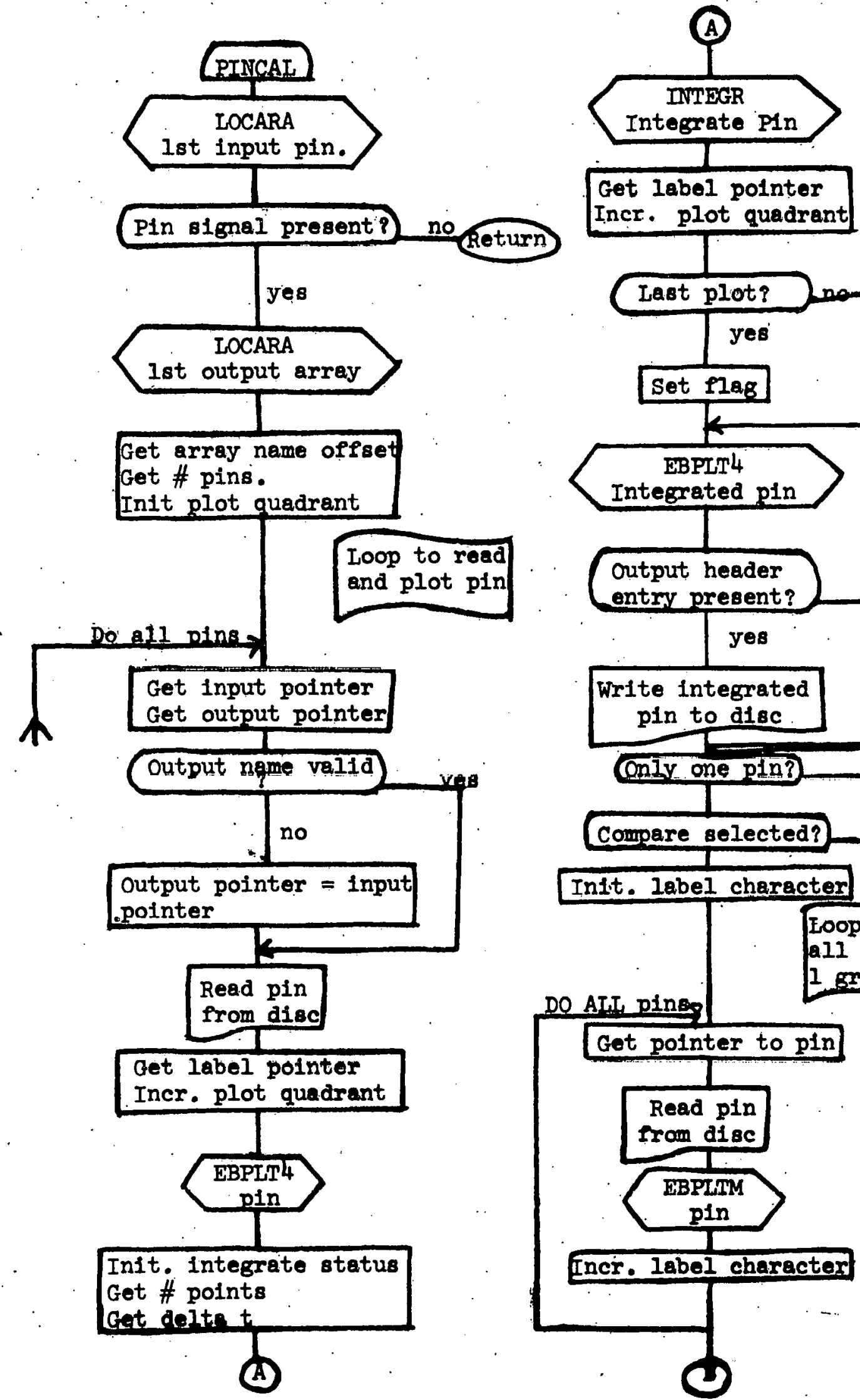

Incr. plot quadrant]

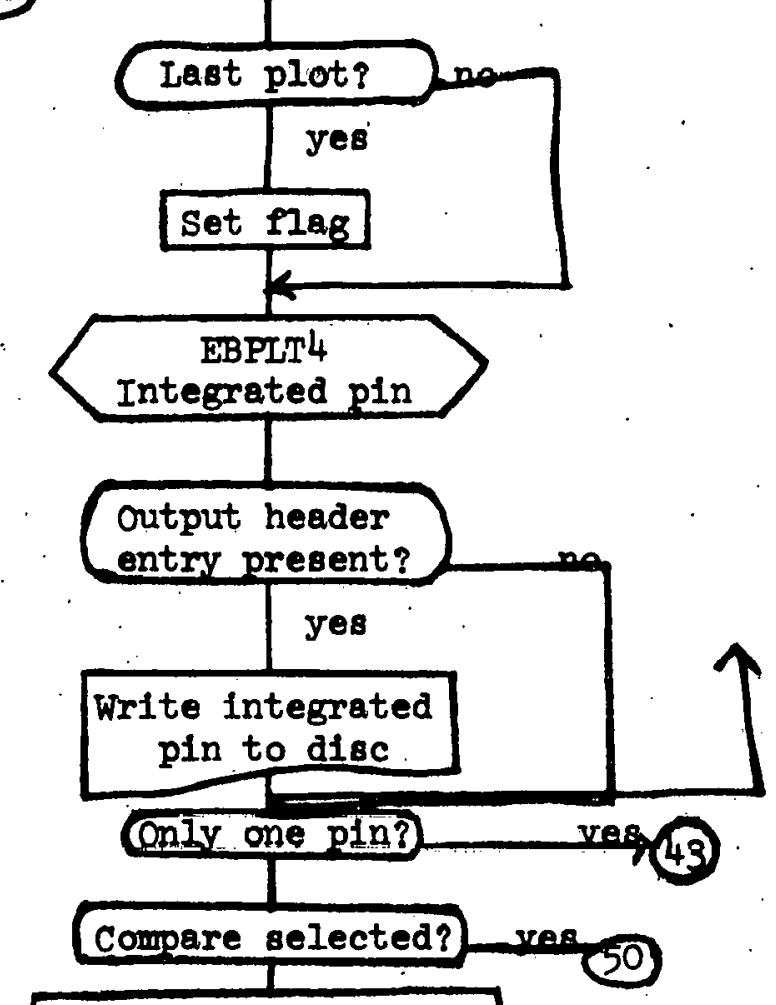

Intt. label character

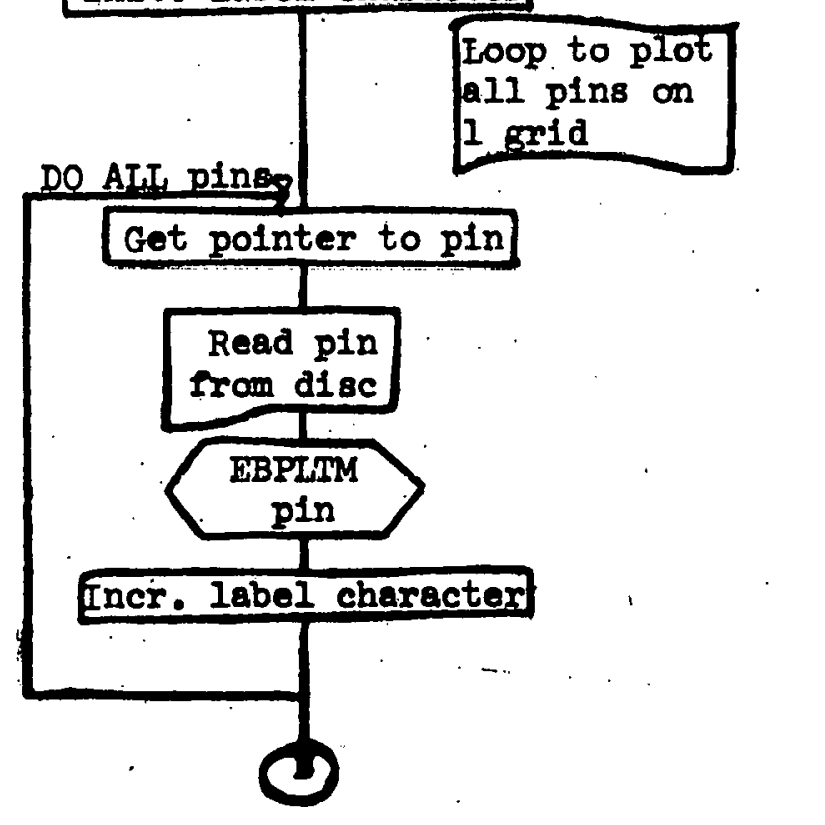




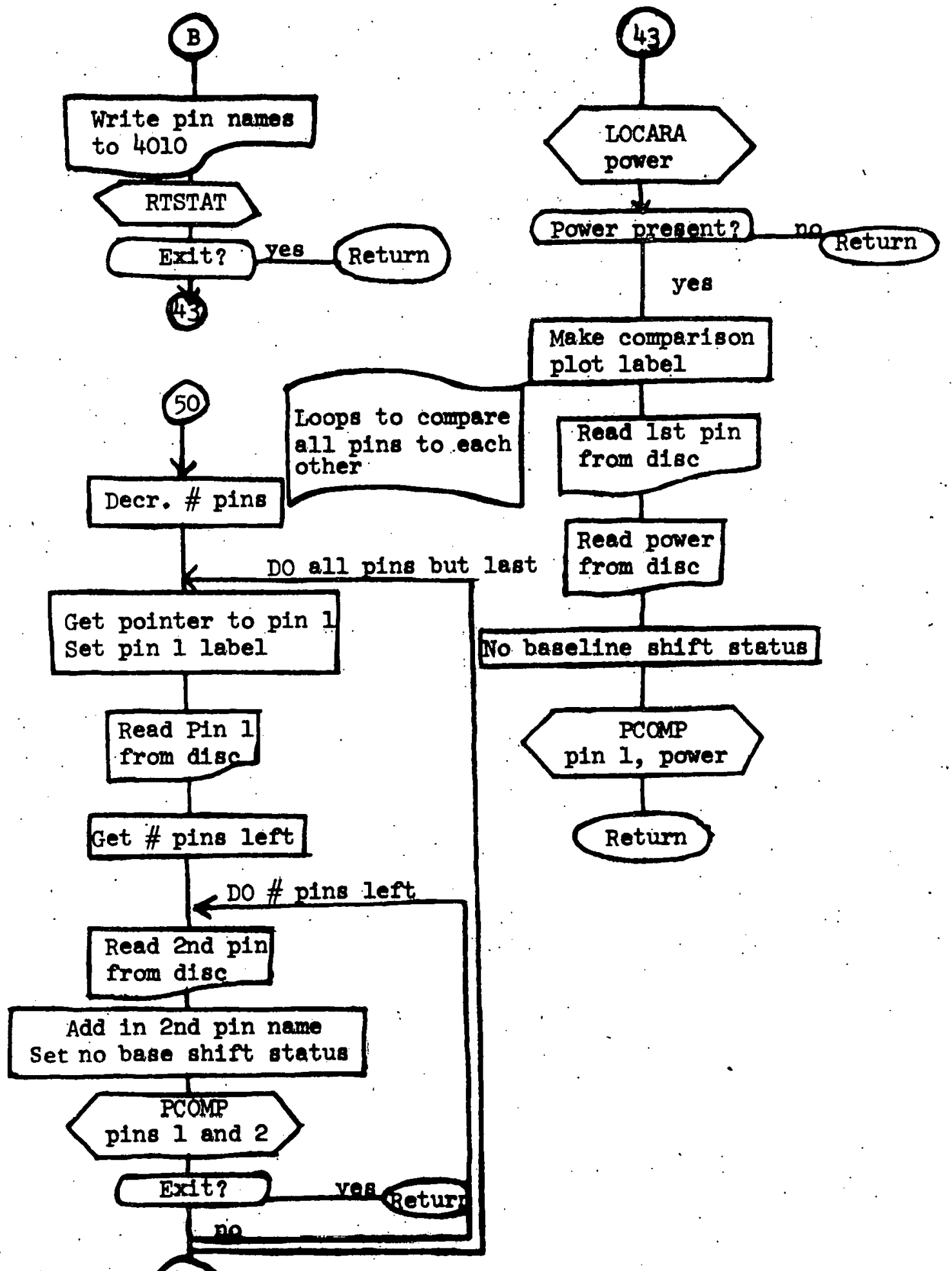

43 
6.14 Fmetion IOCARA - finds location of a given array name in output header.

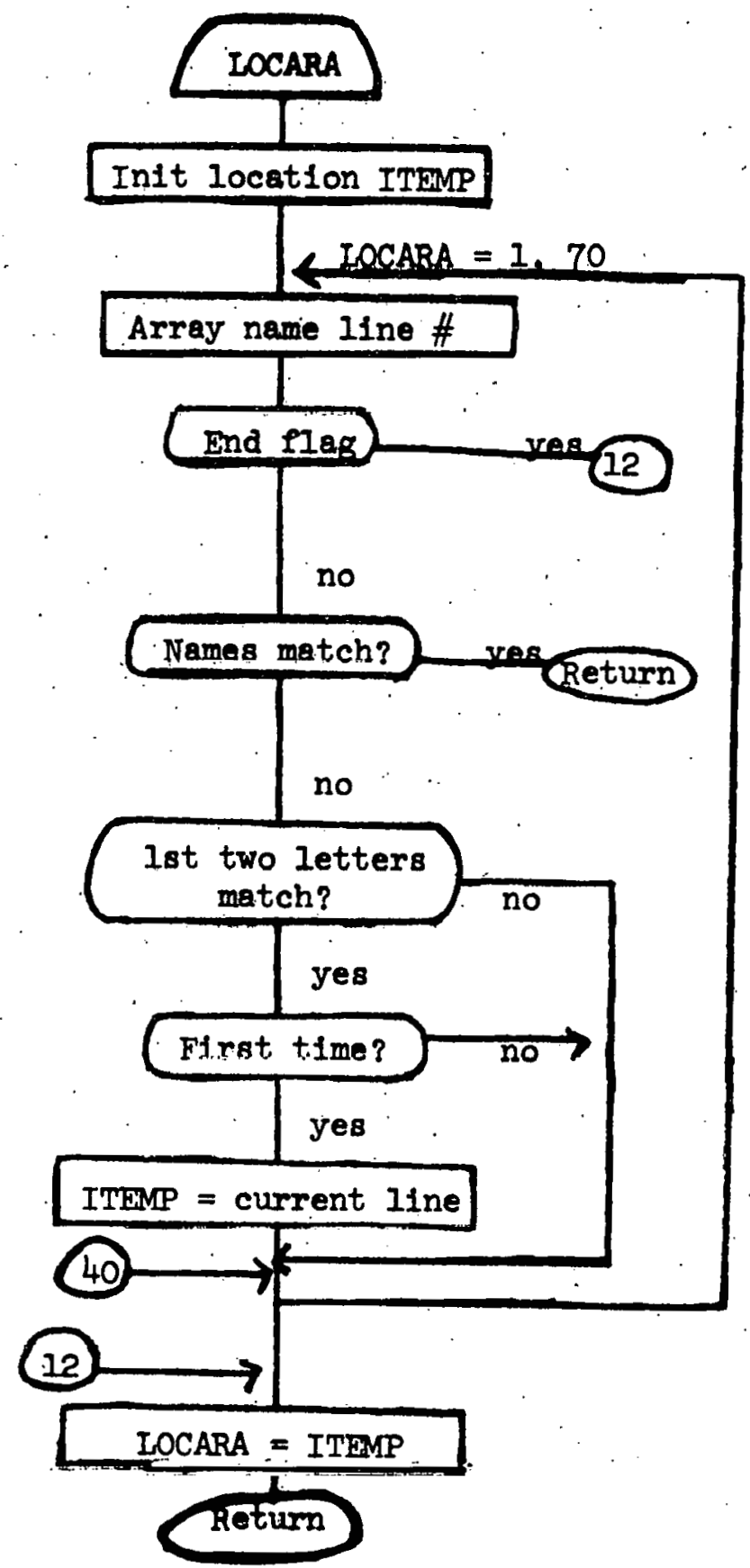


6.I5 Subroutine FCarP - Compares and plote two arrays.

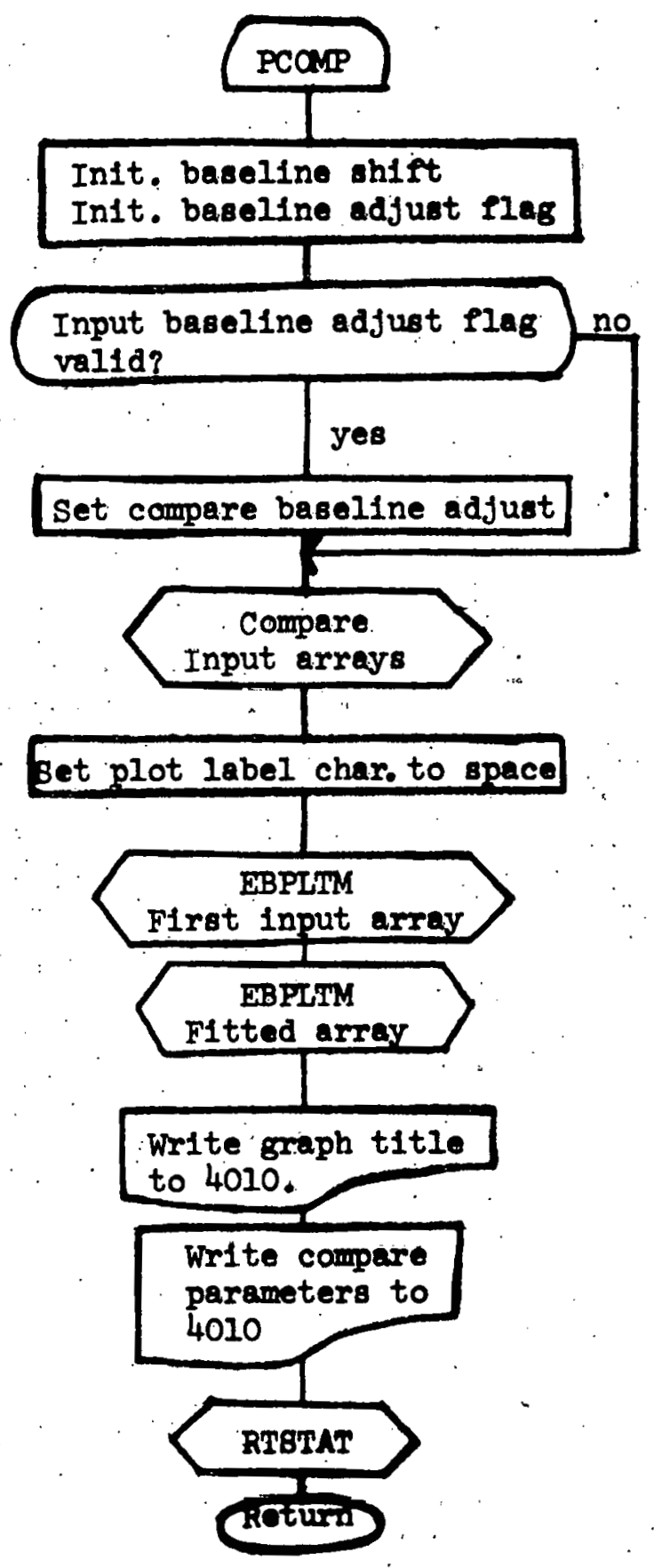


6.10 Subroutine RTSTAT - reade operator return status.

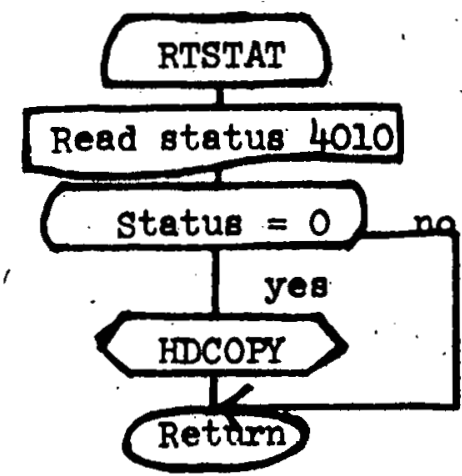

6.17 Subroutine TSHIFT - causes data array to start at $t=0$.

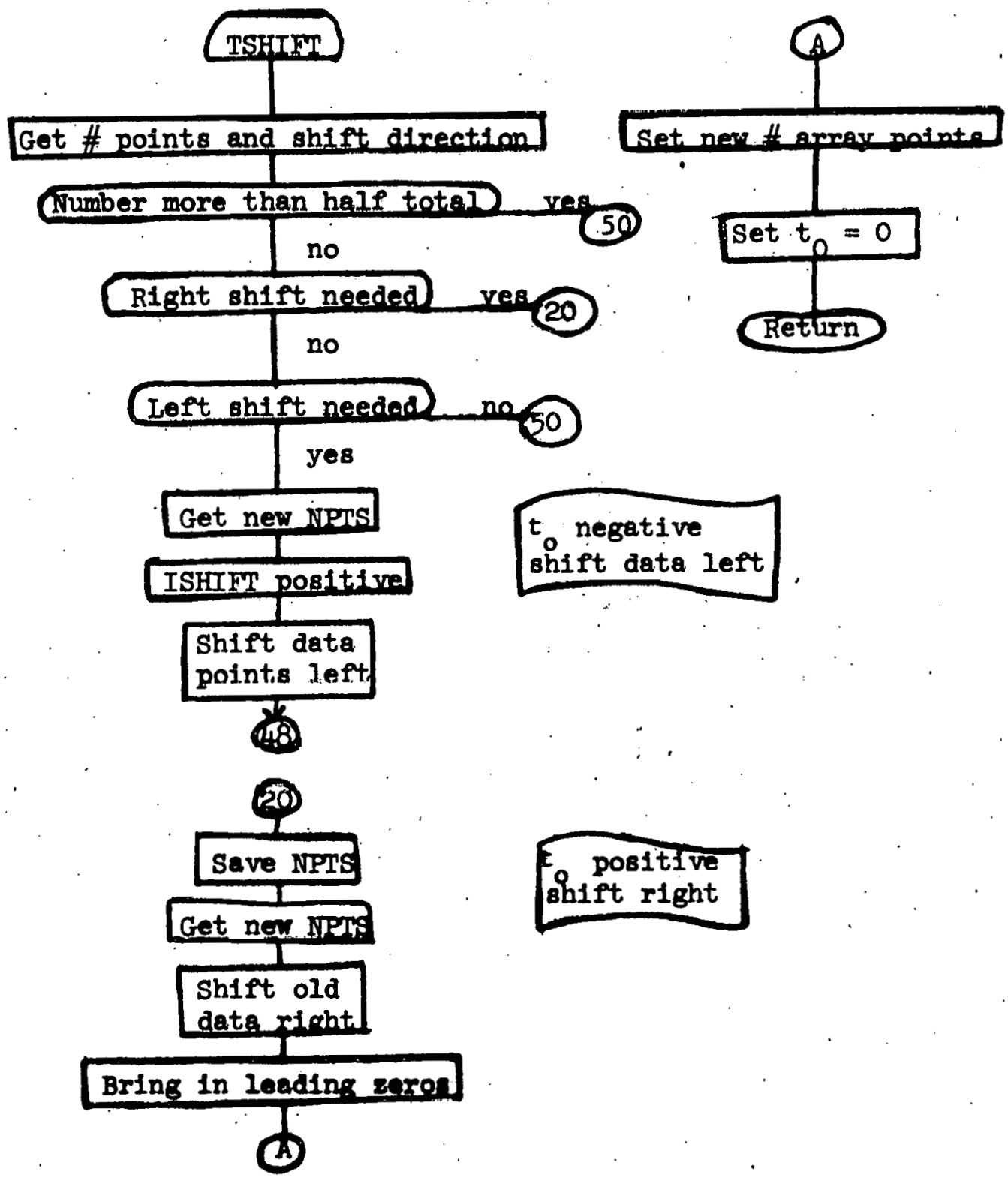


6.18 subroutine ivin - makes two arrage tin consiotint.

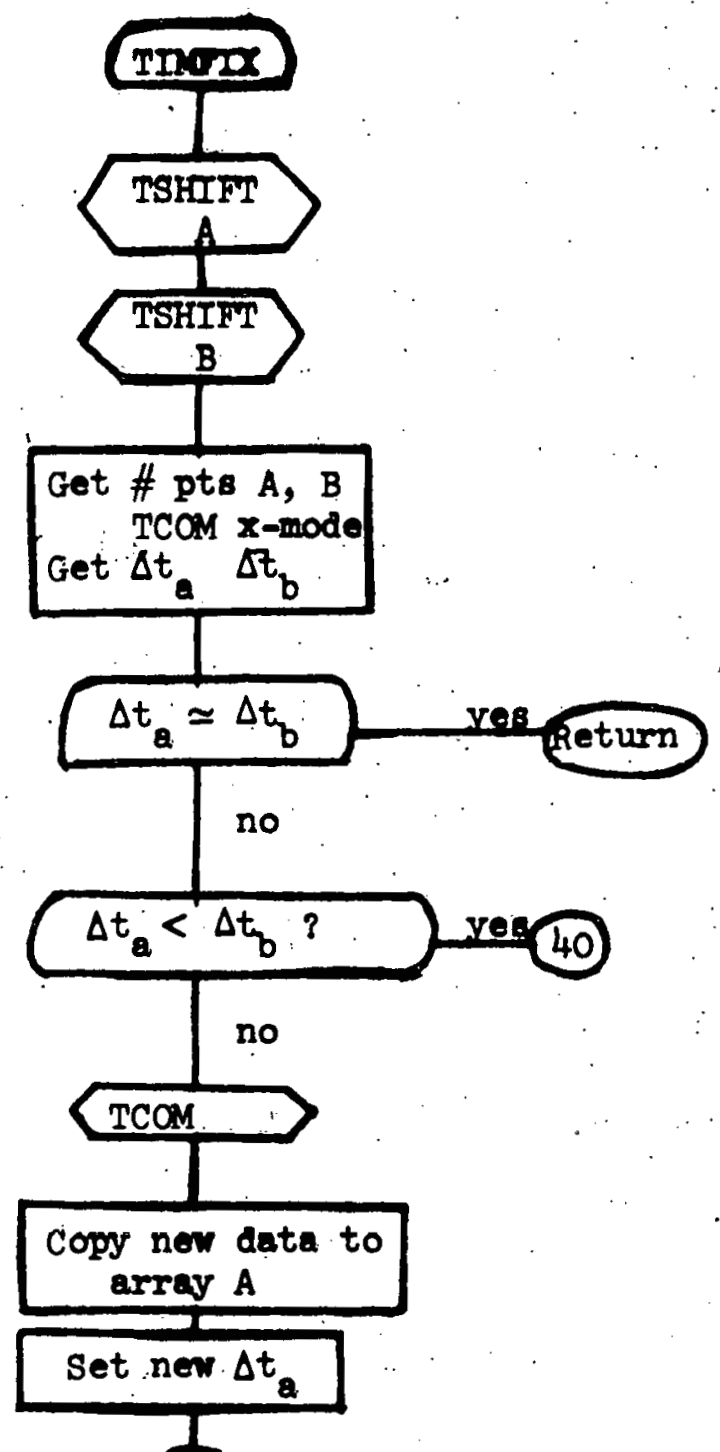

(33)

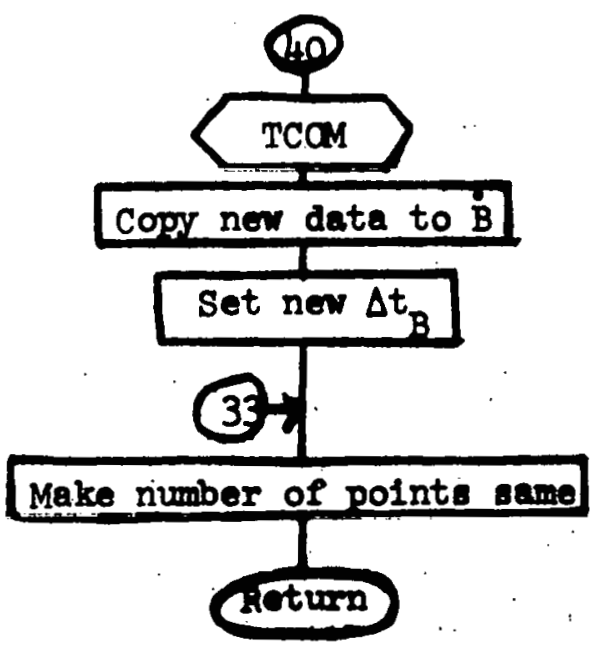




\subsection{Fow chart for TCOM - trancforms arrey to new ampling interval.}
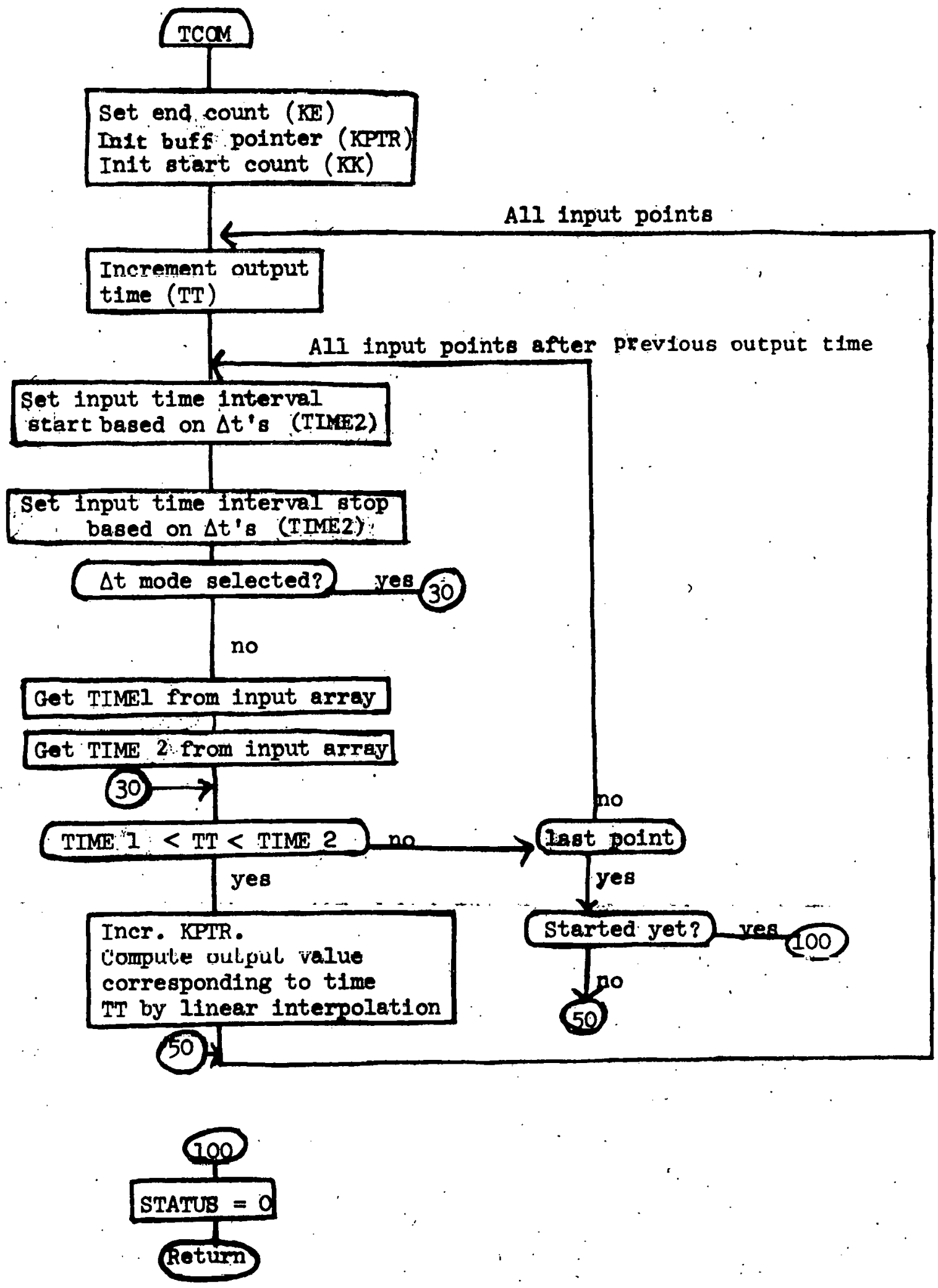


\section{DIODE REFERENCES}

1. Boyer, W. B., Interactive Data Manipulation Program FAWTEK, SANDIA , December 1976.

2. Boyer, W. B., Electron Beam Data Acquisition Program DATAIN, 1976.

3. Boyer, W. B., Electorn Beam Data Acquisition Facility User Manual, SANDIA 5242/5022, September 1976. 
DISTRIBUTION :

TID-4500-R64 UC-2I (206)

R. Martin (WA 52)

Naval Ordnance Systems Command.

Department of the Navy

Washington, DC 20360

Ralph Genario

Physics Internation

2700 Merced Street

San Leandro, CA 94577

Erni Burnholzl (3)

Tektronix Inc.

1258 Ortiz Drive, $\mathrm{SE}$

Albuquerque, NM 87108

1126 R. W. Donahue (3)

5000 A. Narath

5200 E. H. Beckner

5240 G. Yonas

5241 J. Freeman (14)

5242 A. J. Toepfer (12)

5242 W. B. Boyer (25).

5243 G. W. Barr

5244 G. W. Kuswa (10)

5245 . T. H. Martin (9)

$5246^{\circ}$ K. R. Prestwich (9)

8100 L. Gutierrez

3141 C. A. Pepmueller (Actg) (5)

3151 W. L. Carncr (3) 